\title{
Carbon nanomaterials for targeted cancer therapy drugs: a critical review.
}

\author{
HOSNEDLOVA, B., KEPINSKA, M., FERNANDEZ, C., PENG, Q., RUTTKAY- \\ NEDECKY, B., MILNEROWICZ, H.,KIZEK, R.
}

This is the pre-peer reviewed version of the following article: HOSNEDLOVA, B., KEPINSKA, M., FERNANDEZ, C., PENG, Q., RUTTKAY-NEDECKY, B., MILNEROWICZ, H. and KIZEK, R. 2018. Carbon nanomaterials for targeted cancer therapy drugs: a critical review. Chemical record, 19(2-3), pages 502-522, which has been published in final form at https://doi.org/10.1002/tcr.201800038. This article may be used for non-commercial purposes in accordance with Wiley Terms and Conditions for Use of Self-Archived Versions. 
DOI: $10.1002 / x t c r .201800038$

Personal Account

Received: 4.^April.^2018

Accepted: 17.^July.^2018

\section{Carbon Nanomaterials for Targeted Cancer Therapy Drugs: a Critical Review}

Bozena Hosnedlova, ${ }^{[\mathrm{a}]}$ Marta Kepinska, ${ }^{[\mathrm{b}]}$ Carlos Fernandez, ${ }^{[\mathrm{c}]}$ Qiuming Peng, ${ }^{[\mathrm{d}]}$ Branislav

Ruttkay-Nedecky, ${ }^{[a]}$ Halina Milnerowicz, ${ }^{[b]}$ Rene Kizek*[a,b] $^{*}$

[a] <orgDiv/>Department of Human Pharmacology and Toxicology, $<$ orgDiv/>Faculty of Pharmacy, <orgName/>University of Veterinary and Pharmaceutical Sciences Brno, <street/>Palackeho 1946/1, <postCode/>612 42 $<$ city/>Brno, <country/>Czech Republic $<$ phone/>Tel +420 541562820 $<$ fax/>Fax +420541562820

E-mail:kizek@sci.muni.cz

E-mail: bozena.hosnedlova@post.cz

E-mail: brano.ruttkay@seznam.cz

[b] <orgDiv/>Department of Biomedical and Environmental Analyses, <orgDiv/>Faculty of Pharmacy with Division of Laboratory Medicine, <orgName/>Wroclaw Medical University, <street/>Borowska 211, < postCode/>50-556 <city/>Wroclaw, $<$ country/>Poland E-mail: zalewska.m@gmail.com E-mail: halina.milnerowicz@umed.wroc.pl

[c] <orgDiv/>School of Pharmacy and Life Sciences, <orgName/>Robert Gordon University, <street/>Garthdee Road, <city/>Aberdeen < postCode/>AB107GJ, <country/>United Kingdom E-mail: c.fernandez@rgu.ac.uk 
[d] <orgDiv/>State Key Laboratory of Metastable Materials Science and Technology, $<$ orgName/>Yanshan University, < city/>Qinhuangdao < postCode/>066004, $<$ country/ $>$ China

E-mail: pengqiuming@ysu.edu.cn

\section{Cancer}

therapy

carbon nanomaterials

biomedical applications

nanomedicine

Cancer represents one of the main causes of human death in developed countries. Most current therapies, unfortunately, carry a number of side effects, such as toxicity and damage to healthy cells, as well as the risk of resistance and recurrence. Therefore, cancer research is trying to develop therapeutic procedures with minimal negative consequences. The use of nanomaterial-based systems appears to be one of them. In recent years, great progress has been made in the field of possible use of nanomaterials with high potential in biomedical applications. Carbon nanomaterials, thanks to their unique physicochemical properties, are gaining more and more popularity in cancer therapy. They are valued especially for their ability to deliver drugs or small therapeutic molecules to these cells. Through surface functionalization, they can specifically target tumor tissues, increasing the therapeutic potential and significantly reducing the adverse effects of therapy. Their potential future use could, therefore, as vehicles for drug delivery. This review presents the latest findings of research studies using carbon nanomaterials in the treatment of various types of cancer. To carry out this study, different databases such as Web of Science, PubMed, MEDLINE and Google Scholar were employed. The findings of research studies chosen from more than 2000 viewed scientific publications from the last $15^{\wedge \wedge}$ years were compared.

\section{Methodology of the Review}

This review is focused on the physicochemical properties of carbon nanomaterials, such as: active carbon, graphene, graphene oxide, carbon nanofibers, carbon nanotubes, carbon 
nanohorns, carbon nanowalls, fullerenes, nanodiamonds, onion- like carbon), their advantages and potential spectrum of their biomedical use in cancer therapy in humans. The methodology of the choice used scientific studies from more than 2000 viewed articles from the following databases: Web of Science, PubMed, MEDLINE and Google Scholar based on the search phrases, such as: carbon nanomaterials and properties, carbon nanomaterials and cancer/antitumor therapy/cancer therapy, carbon nanotubes and drug delivery/target tumor therapy; and the main findings of various research studies from the years 2002--2017 were discussed.

\section{Introduction}

Cancer belongs worldwide to the leading cause of morbidity and mortality in humans. ${ }^{[1]}$ It is predicted that by 2020 , the number of new cases of cancer in the world will increase to more than 15 million, with deaths increasing to 12 million. ${ }^{[2]}$

There are different cancer treatment approaches, such as: chemotherapy, surgery, radiation and immunotherapy. ${ }^{[3,4]}$ Although chemotherapeutics are the most effective treatment for metastatic tumors, ${ }^{[5]}$ many side effects of chemotherapy have been described, of which the most important are toxic side effects, ${ }^{[6]}$ damage to healthy cells, and tumor recurrence. Moreover, the ability of cancer cells to become simultaneously resistant to different drugs -- a trait known as multidrug resistance -- remains a significant impediment to successful chemotherapy. ${ }^{[5]}$ Conventional chemotherapy also presents other important limitation -- a lack of specificity, resulting in low concentrations of chemotherapeutic drugs at the tumor sites. ${ }^{[6]}$ Therefore, cancer research seeks to develop treatments to minimize these negative side effects, moving on to the most promising cutting-edge therapies, such as gene therapy and nanomedicine. ${ }^{[3]}$

Nanosize systems have pronounced advantages in cancer therapy, starting with their remarkable ability to accumulate at tumor sites, which is much more than in normal tissues due to the enhanced permeability and retention (EPR) effect of tumors. Blood vessels nourishing tumor tissues have larger pore sizes compared with those in healthy tissue, resulting in preferential tumor accumulation of nanosize anticancer drugs, increased treatment 
efficacy and reduced systemic toxicity ${ }^{[7,8]}$ By exploiting the excellent optical and electromagnetic properties of nanomaterials, they are also being employed as thermal nanoscalpels for the ablation of cancer cells. Through surface functionalization, they can be specifically targeted to tumorous tissue allowing for an increase in therapeutic potential and reduction in side effects. ${ }^{[9]}$

Carbon nanomaterials are used for many biological ${ }^{[10--14]}$ as well as biomedical applications, especially for advanced tumor therapy. ${ }^{[15--22]}$ They have potential roles in delivering pharmacologic agents, diagnostic imaging agents, DNA, small interfering RNA, oligonucleotides, and proteins to detect or treat cancer cells. ${ }^{[23,24]}$ These therapeutic applications were probably most described for carbon nanotubes (CNTs).

CNTs, due to their unique physicochemical properties, have become a popular tool in cancer therapy. They are considered to be one of the most promising nanomaterials with the capability of delivering drugs to cancerous cells, ${ }^{[25,26]}$ they were also used for gene therapy and lymphatic targeted chemotherapy. ${ }^{[26]}$ The covalent bond of carbon with oxygen, hydrogen, and nitrogen allows easy routes for functionalization of carbon surfaces with organic or biological molecules. ${ }^{[27]}$ Moreover, their strong optical absorbance in the nearinfrared (NIR) region is useful for photothermal ablation of tumors. ${ }^{[28-30]}$ They have the ability of heat release in a radiofrequency field which can be used to produce thermal cytotoxicity in malignant cells. ${ }^{[31]}$ Therefore, they can be used for photothermal, ${ }^{[32--35]}$ and photodynamic therapy. ${ }^{[26,36]}$ Furthermore, their unique optical properties, such as fluorescence and Raman scattering, make them useful for optical imaging and sensing applications. They have been used as contrast agents for echography, photoacoustic tomography, photothermal and Raman imaging. ${ }^{[37,38]}$

This review focuses primarily on the description of individual types of carbon nanomaterials and their use as vehicles for anticancer drug delivery.

\section{Forms of Carbon Nanomaterials, their Structure, and Synthesis}

Carbon is the $15^{\text {th }}$ most abundant element in the Earth's crust, and the $4^{\text {th }}$ most abundant element in the universe by mass after hydrogen, helium, and oxygen. Its unique 
diversity of organic compounds and its uncommon ability to form polymers at the temperatures usually found on Earth enables this element to serve as a common element of all known life. It is the second most abundant element in the human body by mass (about $\left.18.5^{\wedge} \%\right)$ after oxygen. ${ }^{[39]}$

Carbon can exist in different dimensionalities: from zero- (0D) to three- (3D) dimensional forms. The 2D carbon can be wrapped up into 0D fullerenes, rolled into 1D nanotubes, or stacked into 3D graphite. ${ }^{[40]}$ Based on their bonding structures, nano-carbons may be classified into $\mathrm{sp}^{2}$ - and $\mathrm{sp}^{3}$-carbon nanomaterials. Typical $\mathrm{sp}^{2}$-carbon nanomaterials include 0D fullerene, 1D nanotubes (CNTs), and 2D graphene. Carbon nanoparticles or carbon dots are nano-clusters of amorphous carbon (or composed by small crystalline structures) with sizes smaller than $10^{\wedge \wedge} \mathrm{nm}$ and can be deemed as a type of $0 \mathrm{D} \mathrm{sp}{ }^{2}$-carbon nanomaterials. $\mathrm{sp}^{3}$-carbon nanomaterials, on the other hand, usually are nanodiamonds with crystal sizes in the nano-range. ${ }^{[11]}$ The advents of $\mathrm{sp}^{2}$ and/or $\mathrm{sp}^{3}$ hybridized structures, such as fullerenes, carbon nanotubes, and conducting diamond, provide a route for surface modification. ${ }^{[42]}$ Different allotropes of carbon are shown in Figure ${ }^{\wedge \wedge} 1<$ figr1 $>$. The classification of dimensionality is based on the number of dimensions that are not confined to the nanoscale range $(\mathrm{e} . \wedge \mathrm{g}$. whereas in a $0 \mathrm{D}$ system, all the dimensions are at nanoscale range, 2D nanostructures have two dimensions outside of the nanometric size range. ${ }^{[43]}$ Moreover, techniques have also been developed that have successfully completed the construction of so-called aligned carbon nanotube ropes (CNTRs) $)^{[44-47]}$ with various length of the rope up to tens of $\mu \mathrm{m} .{ }^{[48,49]}$ CNTRs hold promise for next generation of chemical sensors as well as drug delivery systems. ${ }^{[50]}$

\subsection{Activated Carbon}

Activated carbon (AC), also known as charcoal, is an important member of the family of carbon materials. It has an amorphous structure, is chemically stable and is produced from a variety of carbonaceous source materials such as bamboo, wood, coconut shells and coal. ${ }^{[51]}$ Thanks to its strong potential and bio-friendly nature, AC has attracted great attention for medical applications ${ }^{[52--57]}$ e.^g. as a therapeutic agent for treating 
overdoses or acute toxicity through orally ingested drugs, such as diethylcarbamazine ${ }^{[58]}$ and acetaminophen, ${ }^{[59]}$ or even in severe poisonings, ${ }^{[60]}$ and has also been used as a drug delivery system. ${ }^{[61,62]}$ Among carbon-based nanomaterials, AC is considered to be an ideal candidate as a carrier for tumor therapeutic agents. ${ }^{[51]}$

\subsection{Graphenes}

Graphene, a two-dimensional (2D) layer of $\mathrm{sp}^{2}$-bonded carbon, is composed of sixatom rings in a honeycomb network with one-atom thickness. ${ }^{[63]}$ Each carbon atom is bonded to three other carbon atoms, with the $\mathrm{C}<\mathrm{C}->\mathrm{C}$ bond length of $1.42^{\wedge \wedge} \AA$, and a bond angle of $120^{\circ}$. Each carbon atom forms three $\sigma$-bonds via three $\mathrm{sp}^{2}$ hybrid orbitals with three carbon atoms; the rest of the $p$-orbital forms a conjugated system with other contiguous carbon atoms.

Graphite and its allotropes possess exceptional physicochemical properties, such as high fracture strength and Young's modulus, excellent electrical and thermal conductivity, quick charge carrier mobility, large specific surface area, and good biocompatibility, ${ }^{[64-67]}$ and therefore have been widely used in medicine and biotechnology, ${ }^{[68]}$ including in sensitive biosensors, ${ }^{[68--73]}$ drug delivery systems (DDSs), ${ }^{[74]}$ and NIR fluorescence imaging techniques. ${ }^{[75--77]}$

Graphene oxide (GO) is a water-soluble nanomaterial prepared via extensive chemical attack of graphite crystals to introduce oxygen-containing defects in the graphite stack, ${ }^{[78]}$ followed by complete exfoliation of the solid into sheets of atomic thickness by either thermal or mechanical treatments. ${ }^{[79-81]}$ The precise chemical structure of graphite oxide has been the subject of considerable debate over the years, and even to this day, no unambiguous model exists. This is because of sample-to-sample variability, due to the nonstoichiometric atomic composition as well as the lack of precise analytical techniques for characterizing this material. ${ }^{[82]}$ Based on a recently proposed model, GO sheets are composed of planar, graphene-like aromatic domains of random sizes interconnected by a network of cyclohexane-like units in chair configuration which are decorated by hydroxy, epoxy, ether, diol, and ketone groups. ${ }^{[83]}$ 
The optical properties of graphene and GO can facilitate medical imaging. The novel graphitic nanostructures, combined with multi-functionalities including biocompatibility, photoluminescence and drug loading and delivery, suggest promising medical applications of graphene materials. ${ }^{[84]}$

Lu et $^{\wedge \wedge}$ al. ${ }^{[85]}$ demonstrated the ability of water-soluble GO as a platform for the sensitive and selective detection of biomolecules, such as DNA and proteins, in clinical treatment. GO can bind dye-labeled ssDNA (single-stranded DNA) resulting in quenching the fluorescence of the dye. Compared to CNTs, GO is due the low cost and large production scale a promising material for designing biosensors.

The synthesis methods of graphene can be divided into two categories: top-down and bottom-up organic synthetic approaches. ${ }^{[86]}$ To the top-down methods belong 1) mechanical exfoliation, 2) chemical oxidation/exfoliation followed by reduction of graphene derivatives such as graphene oxide. While the bottom-up methods include: 1) epitaxial growth on silicon carbide and other substrates, 2) chemical vapor deposition (CVD), and 3) arc discharging methods. ${ }^{[87]}$ The most common approach for preparing graphene and GO is the Hummers method, ${ }^{[78]}$ in which GO is obtained by adding graphite and $\mathrm{NaNO}_{3}$ to concentrated $\mathrm{H}_{2} \mathrm{SO}_{4}$, followed by $\mathrm{KMnO}_{4}$ as the strong oxidizing agent to oxidize the graphite to $\mathrm{GO} ; 30^{\wedge} \% \mathrm{H}_{2} \mathrm{O}_{2}$ is then added to reduce the remnant oxidizing agent and obtain GO.

\subsection{Carbon Nanofibers and Nanotubes}

Carbon nanofibers (CNFs) are morphologically cylindrical or conical structures ${ }^{[27]}$ with diameters in the range of $100--300^{\wedge \wedge} \mathrm{nm}$ and lengths of a few micrometers (up to $\left.200^{\wedge \wedge} \mu \mathrm{m}\right) .{ }^{[88]}$ The internal structure of CNFs varies and comprises different arrangements of modified graphene sheets. CNFs consist of stacked, curved graphite layers that form cones or cups. The stacked-cone structure is often referred to as a 'herringbone', whereas the stacked cup structure is referred to as a 'bamboo' type. ${ }^{[27]}$

CNFs can be classified into two kinds: highly graphitic and lowly graphitic ones. ${ }^{[8]}$ The former can be prepared either by a catalytic vapor-grown procedure with a metal catalyst 
floating in the reaction media ${ }^{[89--99]}$ or by catalytic CVD with the metal catalyst on a support. $^{[100-107]}$

Vapor-grown carbon fibers possess an extraordinarily high tensile modulus, tensile strength, and high electrical and thermal conductivity. With the decreasing diameter of a vapor-grown carbon fiber, the mechanical properties improve. When the fiber reaches a threshold value of $1^{\wedge \wedge} \mu \mathrm{m}$, which distinguishes the transition from fibers to nanofibers, this improvement becomes more pronounced. ${ }^{[108]}$ The usual diameter of prepared vapor-grown carbon nanofibers ranges from $15^{\wedge \wedge} \mathrm{nm}$ to $100^{\wedge \wedge} \mathrm{nm}$. They are continuous with hollow cores and morphologically resembles multi-walled carbon nanotubes (MWCNTs). ${ }^{[109]}$ Their stiffness and strength in combination with outstanding transport properties enable to develop multifunctional nanofiber composites with excellent physical and mechanical properties. ${ }^{[110]}$

CNFs have a cylindrical shape like CNTs but possess different structural and textural characteristics. ${ }^{[88]}$ The main feature distinguishing nanofibers from nanotubes is the stacking of graphene sheets with varying cross-sectional shapes and cone angles $(\alpha) .{ }^{[27]}$ Nanofibers can have different internal structure -- graphene layers are arranged as concentric cylinders, nested truncated cones, segmented structures, or stacked coins. ${ }^{[109]}$

The difference between CNF and CNT is represented by Figure ${ }^{\wedge} 2<$ figr $2>$. There are two definitions of CNT and CNF. The first one is based on morphology, the other on the structure. In the morphological definition, which is more common, CNT is defined as any graphitic carbon material of a nanometric size possessing a tubular shape, i.^e., a cylinder with a tubular cavity. According to this definition, the main discrepancy between a nanotube and a nanofiber is the absence of a hollow cavity for the latter. ${ }^{[11]}$ The second definition defines it as a nested coaxial array of single-wall nanotubes, each nanotube being formed by a graphene sheet rolled into a cylinder of nanometer size diameter. ${ }^{[112]}$

Carbon nanotubes (CNTs), discovered by Iijima in 1991, are novel-type synthetic nanomaterials with distinct hollow and cylindrical structure. ${ }^{[113]}$ The nanometer-scale structure of CNTs is based on a graphene cylinder, a few nanometers in diameter, which can range in length from a few micrometers to millimeters. ${ }^{[114]}$ CNTs can be looked at as single 
molecules, regarding their small size ( $\sim \mathrm{nm}$ in diameter and $\sim \mu \mathrm{m}$ length), or as quasi-onedimensional crystals with translational periodicity along the tube axis. There are infinitely many ways to roll a sheet into a cylinder, resulting in different diameters and microscopic structures of the tubes. These are defined by the chiral angle, the angle of the hexagon helix around the tube axis. ${ }^{[115]}$

The rolled arrangement from layers of graphene sheets ${ }^{[113]}$ can be structured as singlelayered (single-walled carbon nanotubes SWCNTs), two-layered (double-walled carbon nanotubes, DWCNTs), as well as triple-walled carbon nanotubes (TWCNTs) or multiple layers (multi-walled nanotubes MWCNTs). ${ }^{[16]}$ (Figure^^3<figr3>).

A SWCNT consists of one cylindrical graphene sheet, whereas MWCNT are composed of several nested cylinders with an interlayer spacing of $0.34--0.36^{\wedge \wedge} \mathrm{nm}$ that is close to the typical spacing of turbostratic graphite. There are many possibilities to form a cylinder with a graphene sheet. ${ }^{[117]}$ The three most common configurations are shown in Figure $^{\wedge \wedge} 4<$ figr $4>$. One can roll up the sheet along one of the symmetry axis: this gives either a zigzag tube or an armchair tube. It is also possible to roll up the sheet in a direction that differs from a symmetry axis: one obtains a chiral nanotube, in which the equivalent atoms of each unit cell are aligned on a spiral. Besides the chiral angle, the circumference of the cylinder can also be varied. The whole family of nanotubes is classified as zigzag, armchair, and chiral tubes of different diameters. ${ }^{[118]}$

Chemically functionalized SWCNTs have shown promise in tumor-targeted accumulation in mice exhibiting biocompatibility, excretion, and little toxicity. ${ }^{[119]}$ The most important procedures for SWCNTs synthesis include electric arc discharge, laser ablation and catalytic decomposition of gaseous hydrocarbons ${ }^{[120]}$ as well as CVD. ${ }^{[120-122]}$

\subsection{Carbon Nanoparticles, Nanodots, Nanohorns, Nanowalls, and Nanomesh}

Fluorescent carbon nanoparticles (CNPs) are a potential technological alternative due to their high water solubility, flexibility in surface modification with various chemicals, excellent biocompatibility, good cell permeability, and high photostability. ${ }^{[123,124]}$ CNPs could be utilized both as nontoxic drug delivery system and bio-imaging. ${ }^{[125]}$ Fluorescent CNPs 
have a size of $2--6^{\wedge \wedge} \mathrm{nm}$ and can be synthesized for example via nitric acid oxidation of carbon soot. ${ }^{[126]}$

Carbon nanodots (CNDs) belong to the new class of nanocarbons, which possess several advantages compared to carbon nanotubes. They can be synthesized from different biological resources via simple one-step hydrothermal treatment. ${ }^{[127]}$ Graphene quantum dots (GQDs) can be synthesized by acidic oxidation and exfoliation of pristine MWCNTs. ${ }^{[128,129]}$ Liu et ${ }^{\wedge \wedge}$ al. ${ }^{[130]}$ synthesized highly homogeneous GQDs by using chemical exfoliation of graphite nanoparticles. N-doped GQD can be prepared paralyzing citric acid in the presence of urea. ${ }^{[129]}$

Single-walled carbon nanohorns (SWNHs) share similar structures as SWCNTs, however, in the case of SWNHs, the single graphene sheets are rolled into conical, rather than tubular shapes. Van der Waals forces between open ends of individual SWNHs cause their assembling into spherical structures. ${ }^{[131]}$ The size of SWNHs aggregates is about $80--$ $100^{\wedge \wedge} \mathrm{nm}$, which is optimal for the EPR effect and favors their accumulation into the tumor site when administered with intravenous injection. In addition, SWNHs do not need metal catalysts for the synthesis. Therefore their cytotoxic effects are reduced. ${ }^{[132]}$ The shape of SWNHs requires less energy to be endocytosed than the shape of carbon nanotubes. ${ }^{[131,132]}$ Besides that, SWNHs have larger surface areas and internal storage spaces than carbon nanotubes. Stable poly[maleic anhydride-alt-1-octadecene-poly(ethylene glycol)] $\left(\mathrm{C}_{18} \mathrm{PMH}-\right.$ PEG) modified SWNHs can be prepared by sonicating pristine $\mathrm{SWNHs}$ with $\mathrm{C}_{18} \mathrm{PMH}-\mathrm{PEG}$ for $1^{\wedge \wedge} \mathrm{h}$ and the resulted solution was further purified by ultrafiltration. ${ }^{[132]}$

Carbon nanowalls (CNWs) consist of stacks of graphene sheets standing vertically on a substrate. They have a high aspect ratio (length to diameter), high specific surface area, and excellent electrical properties. ${ }^{[133]}$

Reduced graphene oxide nanomesh (RGONM) arises from graphene oxide nanoplatelets after photocatalytic degradation with $\mathrm{TiO}_{2}$ nanoparticles. Graphene oxide nanomeshes constructed by Akhavan ${ }^{[15]}$ have had approximately $61^{\wedge \wedge} \mathrm{nm}$ in diameter, and the average thickness of the sheets has been evaluated to be approximately $0.9^{\wedge \wedge} \mathrm{nm}$. The average 
size of pores was approximately $8^{\wedge \wedge} \mathrm{nm}$. They have much higher NIR absorption as graphene oxide nanoplatelets, therefore are very suitable for photothermal therapy.

\subsection{Fullerenes}

The fullerenes represent a distinct allotrope in the family of carbon nanomaterials. Their unique cage-like structure and electron-deficient nature lead to fascinating properties, which have made them a promising focus of various research areas. The most known fullerene, $\mathrm{C}_{60}$, has a van der Waals diameter of $10.18^{\wedge \wedge} \AA{ }^{[134]}$ positioning it well within the realm of nanotechnology. The origin of the fullerenes' crucial characteristics lies in the unique hybridization of the strained $\mathrm{C}<\mathrm{C}->\mathrm{C}$ bonds. Whereas the carbon atoms in graphene and CNTs are $\mathrm{sp}^{2}$-hybridised to give hexagonal networks, and the tetrahedral network of diamond is $\mathrm{sp}^{3}$-hybridised, the fullerenes are formed from a network of both hexagons $(1,3,5-$ cyclohexatriene ${ }^{[134]}$ and pentagons ([5]radialene), leading to an average hybridization of $\mathrm{sp}^{2}{ }^{[135]}$ The presence of pentagonal rings introduces a substantial amount of strain into the network, ${ }^{[136]}$ resulting to a rehybridised 3D structure with asymmetric $\pi$ orbitals and thus three key properties: $\left.{ }^{[137]} 1\right)$ they are excellent electron acceptors $\left(\mathrm{C}_{60}\right.$ exhibits six reversible reductions), ${ }^{[138]}$ 2) the exterior of the cages can be decorated using a wide spectrum of chemical reactions, and 3) the relative inertness of the interior of the cages facilitates the capture and isolation of ionic, atomic and even small molecular species. ${ }^{[139]}$ Fullerenes can be synthesized for example by arc discharge method. ${ }^{[140]}$

\subsection{Nanodiamonds, Carbon Onions}

Nanodiamond (ND) particles evince great potential due to their shape and small size (from 4 to $10^{\wedge \wedge} \mathrm{nm}$ in diameter), large surface area as well as the content ratio of the carbon $\mathrm{sp}^{2} / \mathrm{sp}^{3}$ hybridized bonds. ${ }^{[141-144]}$ NDs possess a great potential for biomedical applications, including their use in anticancer therapy. The use of these nanoparticles as anticancer drug carriers (drug delivery systems, DDSs) is the focus of many recent studies. ${ }^{[145--151]}$ The advantage of NDs is, besides the highest biocompatibility of materials, the possibility of delivering the drug to a specific site, thereby maximizing the bioavailability of the drug. ${ }^{[152]}$ 
NDs may be synthesized utilizing various methods, ${ }^{[153]}$ however, the most common cost-effective is the detonation technique. ${ }^{[142,154]}$

Carbon onions consist of spherical closed carbon shells and owe their name to the concentric layered structure resembling that of an onion. Carbon onions are sometimes called carbon nano-onions (CNOs) or onion-like carbon (OLC). All these names represent all kinds of concentric shells, from nested fullerenes to small $\left(<100^{\wedge \wedge} \mathrm{nm}\right)$ polyhedral nanostructures. ${ }^{[155]}$ OLC can be synthesized by many different methods. One of them with a potential for industrial applications uses annealing in inert gases to transform ND, which is currently produced in ton quantities, ${ }^{[156]}$ to OLC.${ }^{[157]}$ Another synthesis techniques represent for example arc discharge between two graphite electrodes in water ${ }^{[158,159]}$ and CVD. ${ }^{[160]}$

\section{Functionalization of Carbon Nanomaterials}

Despite their unique properties, a graphene-based material rarely features the surface characteristics required for certain specific applications. For this reason, surface functionalization is essential, and researchers have devised various covalent and noncovalent chemistries. $^{[161]}$

Graphene sheets without functionalization are insoluble and infusible, which limits their application capabilities. ${ }^{[161]}$ Therefore, efforts have been made to develop solutionprocessable graphene oxides ${ }^{[162--165]}$ and edge-functionalized graphene sheets from exfoliation of graphite powders. ${ }^{[166-168]}$ The invasion of heteroatoms into the hexagonal carbon sheet of pristine graphene unavoidably results to structural and electronic distortions, leading to alterations of graphene properties, such as thermal stability, charge transport, Fermi level, bandgap, localized electronic state, spin density, optical and magnetic properties. Depending on the type of dopants (with particular valence and size) and their bonding configurations, novel or improved properties beneficial for particular applications can appear. ${ }^{[66]}$

Functionalization can significantly improve physicochemical and biological properties of nanomaterials. It can enhance their stability ${ }^{[132]}$ and biocompatibility, ${ }^{[129,132,169]}$ improve colloidal stability in aqueous suspensions, ${ }^{[170]}$ exhibit much higher transport capacities, ${ }^{[171]}$ make favorable pharmacokinetic and toxicology profiles of nanomaterials, ${ }^{[172]}$ evince 
the low dark cytotoxicity and high light cytotoxicity, as well as increase their therapy efficiency. ${ }^{[21]}$ Moreover, it can enhance activation of the immune system. ${ }^{[173,174]}$ For instance, Barhard et ${ }^{\wedge \wedge}$ al. ${ }^{[175]}$ reported a microfluidic-free, sensitive, planar device on treated GO substrates to enable quick and efficient capture of Class-II MHC-positive cells from murine whole blood.

Among commonly used functionalizations of carbon nanomaterials belongs PEGylation. ${ }^{[132,169,172]}$ This surface modification can give to nanomaterials excellent biocompatibility, high storage capacity for anticancer drug and high photothermal conversion efficiency, as well as increase efficiency of the ablation of tumors. ${ }^{[169]}$ Moreover, carbon nanomaterials modified with PEG can display higher blood circulation times and lower accumulation into reticuloendothelial system (RES) organs. ${ }^{[176]}$ The immunologically modified nanostructures can be prepared using the immune-adjuvant glycated chitosan (GC) $)^{[173]}$ which was formulated to enhance the activation of the immune system. ${ }^{[177]} \mathrm{GC}$ is biocompatible, water-soluble, and capable of increasing the concentration of cytokines as well as activating immune cells. ${ }^{[178,179]}$ Additionally, GC can be used as a surfactant. With the synergistic combination of thermal laser irradiation and immunological stimulation, laser immunotherapy is capable of inducing an effective anti-tumor immunological response in late-stage metastatic cancer patients. ${ }^{[180]}$ A stabilization of carbon-encapsulated magnetic nanoparticles in aqueous suspensions can be achieved for example by surface modification using polyvinyl-alcohol (PVA). ${ }^{[170]}$ Nitrogen-doped GQDs (N-GQDs) which were loaded with the anticancer drug, methotrexate (MTX), evinced as an efficient drug delivery system.

For removing defects from CNFs that diminish their electrical and mechanical properties, graphitization is one of the most effective methods used. Heat treatment to $1800^{\wedge}{ }^{\circ} \mathrm{C}$ evinced substantial improvement in mechanical characteristics, while higher temperatures lead to a slight worsening in mechanical properties probably as a result of the elimination of potential bonding sites caused by the elimination of the truncated edges of the graphene layers. The electrical and thermal properties of the resulting nanocomposites improved with the increasing heat-treatment temperature. ${ }^{[10]}$ 
In CNTs, the lack of solubility and the difficult manipulation in any solvents have imposed great limitations on their use. CNTs are fabricated as insoluble in all organic solvents and aqueous solutions. They can be dispersed in some solvents by sonication, but immediately precipitate when this process is interrupted. However, it has been reported that CNTs can interact with different classes of compounds. ${ }^{[181--189]}$ The formation of supramolecular complexes enables better processing of CNTs toward the fabrication of innovative nano-sized devices. Moreover, CNTs can undergo chemical reactions that make them more soluble for their integration into inorganic, organic, and biological systems. ${ }^{[189]}$ Functionalization of CNTs, i.^e., the attachment of appropriate chemical functionalities onto their conjugated $\mathrm{sp}^{2}$ carbon scaffold, enables their potential applications. The derivatized CNTs exhibit improved properties with respect to solubility and ease of dispersion, manipulation as well as processibility. ${ }^{[190]}$

The main approaches for the modification of CNTs are: 1) the covalent attachment of chemical groups through reactions onto the $\pi$-conjugated skeleton of CNTs, 2) the noncovalent adsorption or wrapping of various functional molecules, and 3) the endohedral filling of their empty inner cavity. ${ }^{[189]}$ A typical representation of such surface modifications is depicted in Figure ${ }^{\wedge} 5<$ figr5>. Particular different approaches to chemical modification are shown in Figure ${ }^{\wedge \wedge} 6<$ figr6>.

An interesting modification of carbon nanomaterials can also be cyclodextrins (CDs). ${ }^{[191-193]}$ CDs have been used as complexing agents to enhance aqueous solubility of poorly soluble drugs, and to increase their bioavailability and stability. ${ }^{[194]}$ CDs are known to adsorb easily onto carbonaceous supports. ${ }^{[191-193,195,196]}$ Adsorption of the CDs results in a better dispersion of support used in the aqueous phase. ${ }^{[193]}$ Since it is unlikely that CNTs or nanotube ropes would be the rotaxane structures with the CDs, ${ }^{[197]}$ the CDs are therefore believed to be adsorbed at the surface of nanotube ropes by van der Waals force. ${ }^{[191]}$ The observations of Chen et ${ }^{\wedge} \wedge$ al. ${ }^{[191]}$ demonstrated that CDs have surprisingly distinctly better CNT-dispersing capability. The aqueous dispersion of SWCNTs can be achieved by sonication with $\gamma$-cyclodextrin in deionized water. 
Fullerenes possess unique physical and chemical properties ${ }^{[198]}$ making them suitable for biomedical applications. ${ }^{[199]}$ However, they have, like all carbon-based nanomaterials, ${ }^{[200]}$ a low solubility (less than $0.1^{\wedge \wedge} \mathrm{ng}^{\wedge . \wedge} \mathrm{L}^{<\mathrm{M}->1}$ ) and displays a tendency for aggregation. ${ }^{[201,202]}$ To enhance their hydrophilicity, various functionalizations can be used, e.^g., $<\mathrm{C}->\mathrm{OH},<\mathrm{C}-$ $>\mathrm{COOH},<\mathrm{C}->\mathrm{NH}_{2} \cdot{ }^{[198]}$ The fullerene core appears to be a good drug vector since it greatly enhances the uptake of the cationic groups by the membrane. ${ }^{[199]}$

\section{Applications of Carbon Nanomaterials in the Cancer Therapy}

Use of carbon nanomaterials in cancer therapy includes delivery of drugs ${ }^{[203]}$ or small therapeutic molecules at target sites, using for thermal ablation of tumor cells, ${ }^{\text {[204] }}$ photothermal, ${ }^{[51,205--209]}$ and photodynamic therapies, ${ }^{[51,210--212]}$ as vehicles for gene and nucleic $\operatorname{acid}^{[213,214]}$ delivery, for theranostics and as combined therapy approach.

\subsection{Carbon Nanotubes as Carriers of Anticancer Agents}

Besides their application as mediators for photothermal and photodynamic therapies to directly destroy cancer cells, using combinations of light energy, without severely damaging normal tissue,${ }^{[215]}$ CNTs are also attractive as carriers for cancer therapy. ${ }^{[216]}$ Moreover, it was revealed that CNTs can easily enter all sorts of cells, including mammalian, yeast, as well as bacteria cells. ${ }^{[113]}$ CNTs have high aspect ratios and very small size, and thus they have high specific surface areas, related to their needle-like shapes, enabling them to adsorb onto or conjugate with various therapeutic molecules. The needle-like shape of CNTs also enables their internalization into target cells. ${ }^{[215]}$ Bio-distribution studies have shown high tumor accumulation of functionalized SWCNTs. ${ }^{[19]}$ Therefore, CNTs are considered as promising nanocarriers for the delivery of therapeutic agents. ${ }^{[215]}$ CNTs has been widely investigated for delivery of antitumor agents, including drugs, ${ }^{[217]}$ genes $^{[130,218-220]}$ or DNA, ${ }^{[221,222]}$ plasmid DNA, ${ }^{[223,224]}$ small-interfering RNA (siRNA), ${ }^{[23,225--228]}$ oligonucleotides, and DNA/RNA aptamers. ${ }^{[215,229]}$ CNTs can also deliver proteins ${ }^{[215]}$ and peptides, ${ }^{[230]}$ and immunotherapy components. ${ }^{[215]}$ Sun et ${ }^{\wedge \wedge}$ al. ${ }^{[84]}$ prepared anticancer drug-loaded nano-graphene oxide (NGO) with high capacity, and selectively transported into specific cancer cells by antibody-guided targeting. ${ }^{[84]}$ 
Various options of CNT are employed as carriers of drugs, nucleic acids, and proteins, including the most commonly used conjugated polymers for drug and gene delivery which are depicted in Figure ${ }^{\wedge} 7<$ figr $7>$. Polymers play an integral role in drug delivery technology because provide controlled release of therapeutic agents in constant doses over long periods, cyclic dosage, and tunable release of both hydrophilic and hydrophobic drugs. ${ }^{[231]}$ They offer protection against chemical degradation. Some nanoparticulate polymeric systems possess the ability to cross the blood-brain barrier. In addition, smart polymers are responsive to atmospheric stimuli, such as a change in temperature; pressure, $\mathrm{pH}$, etc., making them extremely beneficial for targeted drug delivery. Moreover, some polymeric systems conjugated with antibodies/specific biomarkers help in detecting molecular targets specifically in cancers. Surface coating with thiolated PEG and Silica-PEG improves water solubility as well as photostability. Furthermore, surface modification of drug carriers, e.^g., attachment with PEG or dextran to the lipid bilayer increases their blood circulation time. Polymer-drug conjugates such as Zoladex, Lupron Depot, On Caspar PEG intron, are used in the treatment of prostate cancer and lymphoblastic leukemia. Nontoxic, biodegradable and biocompatible polymers are available. ${ }^{[232]}$ Biodegradable polymers find widespread use in drug delivery as they can be degraded to non-toxic monomers inside the body. ${ }^{[233]}$

Behnam et ${ }^{\wedge \wedge}$ al. ${ }^{[218]}$ reported that the polyethyleneimine (PEI) derivatives bound to CNTs retained the ability to fully condense plasmid DNA at low N/P (nitrogen to phosphate) molar ratios and substantial buffering capacity in the endosomal $\mathrm{pH}$ range.

\subsection{Carbon Nanomaterials for Anticancer Drug Delivery}

CNT-based nano-vectors, especially functionalized nanotubes, have shown strong potential for therapeutic drug delivery. ${ }^{[234]}$

Through appropriate functionalization, CNTs have been used as nanocarriers for anticancer drugs, such as doxorubicin (DOX), ${ }^{[235]}$ betulinic acid (BA), ${ }^{[236]}$ MTX, ${ }^{[237]}$ gemcitabine (GEM), ${ }^{[238]}$ etoposide, paclitaxel (PTX), ${ }^{[239]}$ chelerythrine, ${ }^{[240]}$ camptothecin (CPT), carboplatin, cisplatin (CIS), ${ }^{[241]} \mathrm{Pt}(\mathrm{II})$, and $\mathrm{Pt}(\mathrm{IV}) .{ }^{[215]}$ 
Tan et^^al. ${ }^{[236]}$ formulated BA, a poorly water-soluble drug, in oxidized MWCNTs (MWCNT-COOH) for enhanced delivery efficiency into cancer cells with reduced cytotoxicity. The MWCNT-BA nanocomposite evinced increased anticancer activity against human lung cancer cell line A549 compared to human liver cancer cell line HepG2. The $\mathrm{IC}_{50}$ for MWCNT-BA in A549 and HepG2 cells was 2.7 and $11.0^{\wedge \wedge} \mu \mathrm{g}^{\wedge \cdot \wedge} \mathrm{mL}^{<\mathrm{M}->1}$, respectively. By comparing the anticancer activity of BA alone $\left(3.5\right.$ and $15.0^{\wedge \wedge} \mu \mathrm{g}^{\wedge \cdot \wedge} \mathrm{mL}^{<\mathrm{M}->1}$ for A549 and HepG2 cells), the studies clearly showed that MWCNT-BA (about $15^{\wedge} \%$ wt of loaded BA) is more potent than the free drug $\left(100^{\wedge} \%\right.$ of BA), with the suggested range of concentrations found to be $<50^{\wedge \wedge} \mu \mathrm{g}^{\wedge . \wedge} \mathrm{mL}{ }^{<\mathrm{M}->1}\left[{ }^{236]}\right.$

The PLGA[poly (lactic-co-glycolic)]-coated CNTs displayed high loading efficiency for paclitaxel, which demonstrated in^^vitro antitumor efficacy against human PC-3MM2 prostate cancer cells. ${ }^{[239]}$ Zhang et ${ }^{\wedge \wedge}$ al. ${ }^{[242]}$ demonstrated a targeted delivery system for DOX based on SWCNTs derivatized with carboxylate groups and coated with a polysaccharide material. There are numbers of studies that display significantly improved the therapeutic efficacy of drug nanocarriers against different tumor models compared to the free drugs. ${ }^{\text {[243-- }}$ 246]

Also, other types of carbon nanomaterials evince a strong potential for anticancer drug delivery. For instance, Bayda et ${ }^{\wedge \wedge} \mathrm{al}^{[247]}$ presented a simple and economical green synthesis using black tea as a suitable precursor for the synthesis of CNPs by nitric acid $\left(\mathrm{HNO}_{3}\right)$ oxidation. CNPs produced by this way are non-toxic and can be utilized for multiplexing applications, e.^g., for efficient delivery of DOX. The biodistribution, pharmacokinetics profiles and kinetics of release show that CNPs -- DOX is an optimal drug delivery vector for cancer therapy. Kim et ${ }^{\wedge \wedge}$ al. ${ }^{[248]}$ demonstrated that mesoporous carbon nanoparticles could serve as a transmembrane carrier for delivering a membrane impermeable fluorescence dye Fura-2 through the cell membrane to release these molecules inside of live human cervical cancer HeLa cells. This finding opens the way for further development of mesoporous carbon nanoparticles as a new generation of nanodevices for transmembrane delivery and intracellular release applications. Gu et ${ }^{\wedge \wedge}{ }^{\wedge} .^{[249]}$ introduced hydrophilic mesoporous carbon 
nanoparticles as carriers for sustained release of hydrophobic anti-cancer drug -camptothecin.

Recently, magnetic GO and magnetic CNTs were ensheathed with mesoporous silica, for the loading and delivery of CPT. The complex of prepared nanomaterials and CPT evinced remarkably high cytotoxicity towards HeLa cell lines compared to the pure drug. ${ }^{[250]}$

Sahoo et ${ }^{\wedge \wedge}$ al. ${ }^{[251]}$ functionalized MWCNTs GO by highly hydrophilic and biocompatible poly(vinyl alcohol) (PVA) for loading and delivery of CPT. MWCNT<C$>$ PVA $<$ C- $>$ CPT and GO $<$ C- $>$ PVA $<$ C- $>$ CPT evinced higher cytotoxic activity compared to free CPT alone, with superior proven effect in MWCNT $<\mathrm{C}->\mathrm{PVA}<\mathrm{C}->\mathrm{CPT}$, interestingly despite that GO sheets are considered to be promising materials for drug delivery due to their surface availability on both sides for drug binding.

CNT drug delivery is considered to possess high efficacy of cancer therapy and using a low doses of drug. In another work, in ${ }^{\wedge} \wedge$ vivo SWCNT drug delivery for tumor suppression in mice was introduced. Other widely used cancer chemotherapy drug -- PTX was conjugated to branched polyethylene glycol chains on SWCNTs. This water-soluble SWNT-PTX conjugate showed higher efficacy in suppressing tumor growth than clinical used Taxol in a murine 4T1 breast cancer model, due to prolonged blood circulation and 10-fold higher tumor PTX uptake by SWCNT delivery most likely through EPR effect. ${ }^{[19]}$

Feazell et ${ }^{\wedge \wedge}$ al. ${ }^{[18]}$ derivatized amine-functionalized soluble SWCNTs with CIS prodrug conjugates as an anticancer drug platform for testicular cancer cells treatment. The cytotoxicity of the free platinum(IV) complex enhanced by $>100$-fold when the complex was attached to the functionalized SWCNTs surface.

Nanoparticles have higher retention times in tumors than in normal tissues owing to the EPR effect of tumors. ${ }^{[252]}$ EPR effect is a unique phenomenon of solid tumors related to their anatomical and pathophysiological differences from normal tissues. In contrast to normal tissues and organs, most solid tumors show a higher vascular density (hypervascularity). ${ }^{[253]}$ For tumor progression, angiogenesis is a crucial factor. Angiogenic blood vessels in tumor tissues, unlike those in normal tissues, have gaps (Figure ${ }^{\wedge \wedge} 8<$ figr8>) as large as 600 to 
$800^{\wedge \wedge} \mathrm{nm}$ between adjacent endothelial cells. ${ }^{[254,255]}$ This defective vascular architecture coupled with poor lymphatic drainage induces the EPR effect, ${ }^{[255,256]}$ leading to the accumulation of nanocarriers at the site of tumor tissue ${ }^{[252]}\left(\right.$ Figure $^{\wedge \wedge} 8<x$ xigr8 $\left.>\right)$. The accumulation of nanoparticles in tumors is affected by several factors, including the size, the surface characteristics of the nanoparticles and the degree of angiogenesis of the tumor. ${ }^{[252]}$ Nanocarrier-based anticancer drugs accumulate in tumor tissue by EPR effect with much stronger activity than the free drugs. ${ }^{[243]}$

Besides designing of nanomaterials targeted in tumor tissue without highly selective semipermeable membrane barrier, nanoparticles also can be formulated to deliver drugs across several biological barriers. ${ }^{[257,258]}$ An efficiency of antineoplastics and some other types of drugs are considerably limited due to their inability to cross the bloodbrain barrier (BBB). The use of nanoparticles to deliver across this barrier appears to be very promising. It has been found that nanoparticles can cross the BBB following the opening of tight junctions by hyper-osmotic mannitol, which also can provide sustained delivery of therapeutic agents for difficult treated diseases such as brain tumors. ${ }^{[259]}$ Also Tween 80coated nanoparticles are able to cross the BBB. ${ }^{[260]}$ Figure $^{\wedge \wedge} 8<x$ figr $8>$ demonstrates a comparison of EPR effect in hepatocellular carcinoma (HCC) and the assumed EPR in tumor tissue with BBB.

It was reported that macromolecules like albumin, leak out more from tumor vessels,

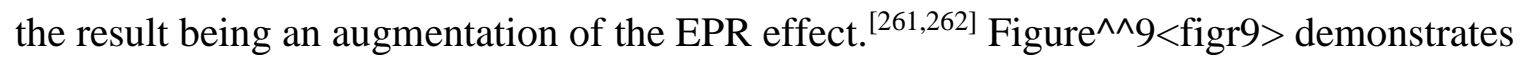
internalization of human serum albumin (HSA) bound to MWCNTs, which was incorporated into vesicles containing membrane protein Gp60.

Despite the widespread use of drug delivery CNTs, some important issues are not entirely solved, such as long-term cytotoxicity in the body, lack of size uniformity during the synthetic process, loading deviations for drug-CNT complexes, and release controllability at the target point. If these limitations are overcome, it can be assumed that CNTs will become one of the strongest tools for cancer therapy. ${ }^{[215]}$

\section{Conclusion and Future Perspectives}


With the global rise in the incidence of various cancers and due to the many known side effects of conventional therapy, it is necessary to develop new ways of more effective and gentler treatment of these diseases. Nanostructured materials that are able to circulate in the body possess high potential in this respect. Carbon nanomaterials are currently intensively being developed for cancer therapy, including drug and gene delivery. Despite this considerable progress, their widespread applications are still considered with apprehension due to possible toxicity risks. However, some carbon nanomaterials, like nanodiamonds, were found to be highly biocompatible and almost nontoxic, and as some research studies have shown, toxic effects of others can be reduced by their suitable chemical functionalization, while also increasing their biocompatibility. The appropriate functional modification also enables to eliminate their poor water solubility and thus to remove dispersion problems in an aqueous medium. Moreover, the indisputable advantage that makes the carbon nanomaterials quite unique is their ability to cross the membranes of many different types of cells passively. In addition, nanocarriers can be accumulated preferentially at tumor sites by the EPR effect, resulting in increased selective targeting and improved drug efficacy. All these advantages suggest the potential exploitation of carbon nanomaterials for drug administration. Therefore, a great task of scientists for the coming years will be the development of novel functionalization strategies for further improvement of surface characteristics of carbon nanomaterials that would improve the additional controlled release of the drug transported at the target site and would also lead to the elimination of concerns about toxicity. Overcoming these obstacles, carbon nanomaterials become one of the most powerful tools available for cancer treatment in the near future.
Abbreviations
AC activated carbon
BA betulinic acid
BBB blood-brain barrier
CDs cyclodextrins
CIS cisplatin 
CNFs carbon nanofibers

CNTs carbon nanotubes

CNTRs carbon nanotube ropes

CNPs carbon nanoparticles

CPT camptothecin

CVD chemical vapor deposition

DOX doxorubicin

DDSs drug delivery systems

DWCNTs double-walled carbon nanotubes

EDC $(\mathrm{EDC} \cdot \mathrm{HCl}) \quad N$-(3-dimethylaminopropyl)- $N$ '-ethylcarbodiimide hydrochloride

EPR enhanced permeability and retention

GC glycated chitosan

GO graphene oxide ${ }^{[20]}$

HSA human serum albumin

MTX methotrexate

MWCNTs multi-walled carbon nanotubes

NHS $N$-hydroxysuccinimide

NIR near-infrared

OLC onion-like carbon

PAM polyacrylamide

$\mathrm{PA} m \mathrm{PV} \quad \operatorname{poly}\left\{(5\right.$-alkoxy- $m$-phenylenevinylene $)-c o-\left[\left(2,{ }^{\wedge} 5\right.\right.$-dioctyloxy- $p$-phenylene $)$ vinylene]\}

PEG polyethylene glycol

PEI polyethyleneimine 
PLGA poly(D,L-lactide-co-glycolide)

PmPV poly $\{(m$-phenylenevinylene $)-c o-[(2, \wedge 5$-dioctyloxy- $p$-phenylene $)$ vinylene $]\}$

PPyPV poly $\left\{(2,6\right.$-pyridinylenevinylene $)-c o-\left[\left(2,{ }^{\wedge} 5\right.\right.$-dioctyloxy- $p$-phenylene $)$ vinylene $\left.]\right\}$

PSS polystyrene sulfonate

PVP polyvinyl pyrrolidone

PTX paclitaxel

ssDNAsingle-stranded DNA

SWNHs $\quad$ single walled carbon nanohorns

TWCNTs triple-walled carbon nanotubes

\section{Acknowledgments}

The authors would like to thank $\langle$ cgs $>$ The League Against Cancer Prague $</$ cgs $>(\langle\operatorname{cgn}>260 / L P R / 2018</$ cgn $>)$ and The European Technology Platform for Nanomedicine for their cooperation.

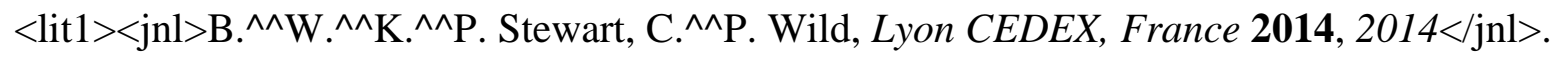

$<$ lit2><jnl>P. Kanavos, Ann. Oncol. 2006, 17, viii15--viii23</jnl>.

$<$ lit3 $><$ jnl >M. Arruebo, N. Vilaboa, B. Sáez-Gutierrez, J. Lambea, A. Tres, M. Valladares, Á.

González-Fernández, Cancers 2011, 3, 3279--3330</jnl>.

$<$ lit4><jnl>E. Lee, J. Koo, T. Berger, Int. J. Dermatol. 2005, 44, 355--360</jnl>.

$<$ lit5 $><$ jnl $>$ M. ${ }^{\wedge}$ M. Gottesman, T. Fojo, S.^^E. Bates, Nat. Rev. Cancer 2002, 2, 48-$58</$ jnl $>$.

$<$ lit6><jnl>S.^^Y. Madani, N. Naderi, O. Dissanayake, A. Tan, A.^^M. Seifalian, Int. J.

Nanomed. 2011, 6, 2963</jnl>.

$<$ lit7><jnl>A. Fernandez-Fernandez, R. Manchanda, A.^^J. McGoron, Appl. Biochem. Biotechnol. 2011, 165, 1628--1651</jnl>.

$<$ lit8><jnl>E. ${ }^{\wedge \wedge}$ S. Shibu, M. Hamada, N. Murase, V. Biju, J. Phytochem. Photobiol. C Photechem. Rev. 2013, 15, 53--72</jnl $>$. 
$<$ lit9><jnl>A. Sawdon, E. Weydemeyer, C.-A. Peng, J. Biomed. Nanotechnol. 2014, 10, 1894--1917</jnl>.

$<$ lit10 $><$ jnl $>$ P.^^K. Boruah, B. Sharma, N. Hussain, M.^^R. Das, Chemosphere 2017, 168, $1058--1067</$ jnl $>$.

$<$ lit11 $><$ jnl $>$ T. ${ }^{\wedge}$ C. Canevari, T. ${ }^{\wedge}$ M. Prado, F. ${ }^{\wedge}$ H. Cincotto, S. ${ }^{\wedge}$ A. Machado, Mater. Res. Bull. 2016, 76, 41--47</jnl>.

$<$ lit12><jnl>X. Hou, S. Lei, S. Qiu, L. Guo, S. Yi, W. Liu, Food Chem. 2014, 153, 121-$129</$ jnl $>$.

$<$ lit13><jnl>D. Koushik, S.^^S. Gupta, S.^^M. Maliyekkal, T. Pradeep, J. Hazard. Mater. 2016, 308, 192--198</jnl >.

$<$ lit14><jnl >D. Pantarotto, C.^^D. Partidos, J. Hoebeke, F. Brown, E. Kramer, J.-P. Briand, S. Muller, M. Prato, A. Bianco, Chem. Biol. 2003, 10, 961--966</jnl>.

$<$ lit15><jnl >O. Akhavan, E. Ghaderi, Small 2013, 9, 3593--3601</jnl >.

$<$ lit16><jnl>X. Bian, Z.-L. Song, Y. Qian, W. Gao, Z.-Q. Cheng, L. Chen, H. Liang, D. Ding, X.-K. Nie, Z. Chen, Sci. Rep. 2014, 4, 6093</jnl>.

$<$ lit17><jnl>K. Erdmann, J. Ringel, S. Hampel, M.^^P. Wirth, S. Fuessel, Belst. J.

Nanotechnol. 2017, 8, 1307</jnl>.

$<$ lit18><jnl>R.^^P. Feazell, N. Nakayama-Ratchford, H. Dai, S.^^J. Lippard, J. Am. Chem. Soc. 2007, 129, 8438--8439</jnl>.

$<$ lit19><jnl>Z. Liu, X. Sun, N. Nakayama-Ratchford, H. Dai, ACS Nano 2007, 1, 50-$56</$ jnl $>$.

$<$ lit20><jnl $>$ S. Gurunathan, J.^^W. Han, J.^^H. Park, E. Kim, Y.-J. Choi, D.-N. Kwon, J.-H. Kim, Int. J. Nanomed. 2015, 10, 6257</jnl>.

$<$ lit21><jnl>J. Liu, K. Liu, L. Feng, Z. Liu, L. Xu, Biomater. Sci. 2017, 5, 331--340</jnl>. $<$ lit22><jnl>Y.^^S. Youn, D.^^S. Kwag, E. ${ }^{\wedge}$ S. Lee, J. Pharm. Invest. 2017, 47, 1--10</jnl>. 
$<$ lit23><jnl>Z. Zhang, X. Yang, Y. Zhang, B. Zeng, S. Wang, T. Zhu, R.^^B. Roden, Y.

Chen, R. Yang, Clin. Cancer Res. 2006, 12, 4933--4939</jnl>.

$<$ lit24><jnl>N.^^W.^^S. Kam, Z. Liu, H. Dai, J. Am. Chem. Soc. 2005, 127, 12492-$12493</ \mathrm{jnl}>$.

$<$ lit25><jnl>M. Adeli, M. Ashiri, B. ${ }^{\wedge}$ K. Chegeni, P. Sasanpour, J. Iran. Chem. Soc. 2013, 10, 701--708</jnl $>$.

$<$ lit26><jnl>S.-r. Ji, C. Liu, B. Zhang, F. Yang, J. Xu, J. Long, C. Jin, D.-1. Fu, Q.-x. Ni, X.-j.

Yu, Biochem. Biophys. Acta BBA Rev. Cancer 2010, 1806, 29--35</jnl>.

$<$ lit27><jnl>A.^^V. Melechko, R. Desikan, T.^^E. McKnight, K. ${ }^{\wedge \wedge}$ L. Klein, P.^^D. Rack, $J$.

Phys. D 2009, 42, 193001</jnl>.

$<$ lit28><jnl>N.^^W.^^S. Kam, M. O'Connell, J.^^A. Wisdom, H. Dai, Proc. Natl. Acad. Sci. USA 2005, 102, 11600--11605</jnl > .

$<$ lit29><jnl>K. Kostarelos, A. Bianco, M. Prato, Nat. Nanotechnol. 2009, 4, 627--633</jnl>. $<$ lit30><jnl>R. Singh, S.^^V. Torti, Adv. Drug Delivery Rev. 2013, 65, 2045--2060</jnl>. $<$ lit31><jnl>C. ${ }^{\wedge}$ J. Gannon, P. Cherukuri, B. ${ }^{\wedge} I$ I. Yakobson, L. Cognet, J.^^S. Kanzius, C.

Kittrell, R.^^B. Weisman, M. Pasquali, H.^^K. Schmidt, R.^^E. Smalley, Cancer 2007, $110,2654--2665</ \mathrm{jnl}>$.

$<$ lit32 $><$ jnl $>$ J.-W. Kim, E. ${ }^{\wedge \wedge}$ I. Galanzha, E. ${ }^{\wedge}$ V. Shashkov, H.-M. Moon, V.^^P. Zharov, Nat. Nanotechnol. 2009, 4, 688</jnl $>$.

$<$ lit33><jnl>J.^^ T. Robinson, K. Welsher, S.^^M. Tabakman, S.^^P. Sherlock, H. Wang, R.

Luong, H. Dai, Nano Res. 2010, 3, 779--793</jnl>.

$<$ lit34><jnl>S. Sarkar, J. Fisher, C. Rylander, M.^^N. Rylander, J. Biomech. Eng. 2010, 132, $044505</$ jnl $>$.

$<$ lit35><jnl>F. Zhou, X. Da, Z. Ou, B. Wu, D. ${ }^{\wedge}$ E. Resasco, W.^^R. Chen, J. Biomed. Opt. 2009, $14,021009</$ jnl $>$. 
$<$ lit36><jnl>B. Tian, C. Wang, S. Zhang, L. Feng, Z. Liu, ACS Nano 2011, 5, 7000-$7009</$ jnl $>$.

$<$ lit37><jnl>L.^^G. Delogu, G. Vidili, E. Venturelli, C. Ménard-Moyon, M.^^A. Zoroddu, G. Pilo, P. Nicolussi, C. Ligios, D. Bedognetti, F. Sgarrella, Proc. Natl. Acad. Sci. USA 2012, 109, 16612--16617</jnl >.

<lit38><jnl>H. Gong, R. Peng, Z. Liu, Adv. Drug Delivery Rev. 2013, 65, 1951--1963</jnl>. $<$ lit39><book>J.^^B. Reece, L. ${ }^{\wedge \wedge}$ A. Urry, M.^^L. Cain, S.^^A. Wasserman, P.^^V.

Minorsky, R.^^B. Jackson, Campbell biology. Editor, Pearson Higher Ed, 2013</book>. $<$ lit40><book>L. ${ }^{\wedge}$ G. De $e^{\wedge \wedge}$ Arco, Y. Zhang, C. Zhou, in Graphene-Synthesis,

Characterization, Properties and Applications, InTech, 2011</book>.

$<$ lit41 ><jnl >Z. Liu, X.-J. Liang, Theranostics 2012, 2, 235</jnl >.

$<$ lit42><jnl>L. Tang, Y. Wang, Y. Li, H. Feng, J. Lu, J. Li, Adv. Funct. Mater. 2009, 19, $2782--2789</ j n l>$.

$<$ lit43><jnl>J.^^N. Tiwari, R. ${ }^{\wedge} N$ N. Tiwari, K.^^S. Kim, Prog. Mater. Sci. 2012, 57, 724-$803</$ jnl $>$.

$<$ lit44><jnl>P. Delaney, H.^^J. Choi, J. Ihm, S.^^G. Louie, M.^^${ }^{\wedge}$ L. Cohen, Nature 1998, 391, $466</$ jnl $>$.

$<$ lit45 $><$ jnl $>$ A. Thess, R. Lee, P. Nikolaev, H. Dai, P. Petit, J. Robert, C. Xu, Y.^^H. Lee, S.^^G. Kim, A.^^G. Rinzler, Science 1996, 273, 483--487</jnl>.

<lit46><book>R. Penner, X. Li, in Book Electrodeposited Carbon Nanotube Ropes,

Decorated with Electrodeposited Pd Nanoparticles for Fast, Sensitive, and Wide-

Range, H2 Sensors, ed., by Editor, The Electrochemical Society, City, 2017, Chap.

Chapter, pp.^^1187--1187</book>.

$<$ lit47><jnl>I. Ostanin, R. Ballarini, D. Potyondy, T. Dumitrică, J. Mech. Phys. Solids 2013, 61, 762--782</jnl $>$. 
$<$ lit48><jnl >M. Terrones, N. Grobert, J. Olivares, J. Zhang, H. Terrones, K. Kordatos, W.

Hsu, J. Hare, P. Townsend, K. Prassides, Nature 1997, 388, 52</jnl>.

$<$ lit49><jnl>J.-J. Shang, Q.-S. Yang, X.-H. Yan, X.-Q. He, K.-M. Liew, Nanomaterials 2016, $6,177</$ jnl $>$.

$<$ lit50><jnl>H. Liang, M. Upmanyu, Carbon 2005, 43, 3189--3194</jnl>.

$<$ lit51 $><$ jnl $>$ M. Chu, J. Peng, J. Zhao, S. Liang, Y. Shao, Q. Wu, Biomaterials 2013, 34, $1820--1832</$ jnl $>$.

$<$ lit52 $><$ book $>$ R.^^C. Bansal, M. Goyal, Activated carbon adsorption. Editor, CRC press, $2005</$ book $>$.

$<$ lit53><jnl>J. He, S. Li, W. Shao, D. Wang, M. Chen, W. Yin, W. Wang, Y. Gu, B. Zhong, J. Surg. Oncol. 2010, 102, 676--682</jnl >.

$<$ lit54><book>S. Mikhalovsky, V. Nikolaev, in Interface Science and Technology, Elsevier, 2006, Vol.^^7, pp.^^529--561</book>.

$<$ lit55 $><$ jnl $>$ H. Negishi, M. Takeda, T. Fujimoto, Y. Todo, Y. Ebina, H. Watari, R.

Yamamoto, H. Minakami, N. Sakuragi, Gynecol. Oncol. 2004, 94, 161--166</jnl>.

<lit56><jnl>S. Watarai, M. Koiwa, J. Dairy Sci. 2008, 91, 1458--1463</jnl>.

$<$ lit57><jnl>Q. Yang, X.-d. Wang, J. Chen, C.-X. Tian, H.-j. Li, Y.-j. Chen, Q. Lv, Tumor

Biol. 2012, 33, 2341--2348</jnl >

$<$ lit58 $><$ jnl $>$ O.$^{\wedge \wedge}$ E. Orisakwe, N.^^A. Ilondu, O.^^J. Afonne, S.^^I. Ofoefule, C. ${ }^{\wedge \wedge}$ N. Orish,

Pharmacol. Res. 2000, 42, 167--170</jnl>.

<lit59><jnl>H.^^A. Spiller, T.^^S. Sawyer, J. Med. 2007, 33, 141--144</jnl>.

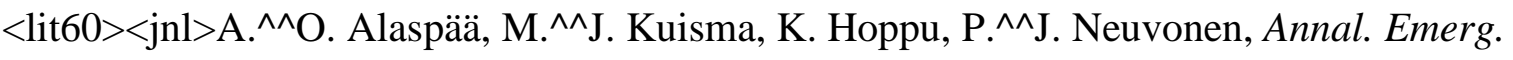

Med. 2005, 45, 207--212</jnl >

$<$ lit61 ><jnl>A. Hagiwara, T. Takahashi, K. Kitamura, C. Sakakura, M. Shirasu, M. Ohgaki,

T. Imanishi, J. Yamasaki, J. Gastroenterol. 1997, 32, 141--147</jnl>. 
$<$ lit62><jnl>A. Hagiwara, T. Torii, K. Sawai, C. Sakakura, M. Shirasu, M. Ohgaki, T. Imanishi, J. Yamasaki, T. Takahashi, Hepato-Gastroenterology 2000, 47, 575-$578</$ jnl $>$.

$<$ lit63><jnl >L. Feng, L. Wu, X. Qu, Adv. Mater. 2013, 25, 168--186</jnl>.

$<$ lit64><jnl>D. Chen, H. Zhang, Y. Liu, J. Li, Energy Environ. Sci. 2013, 6, 1362-$1387</$ jnl $>$.

$<$ lit65><jnl>A.^^K. Geim, Science 2009, 324, 1530--1534</jnl>.

$<$ lit66><jnl >X. Wang, G. Sun, P. Routh, D.-H. Kim, W. Huang, P. Chen, Chem. Soc. Rev. 2014, 43, 7067--7098</jnl >.

$<$ lit67><jnl>K. Yang, S. Zhang, G. Zhang, X. Sun, S.-T. Lee, Z. Liu, Nano Lett. 2010, 10, $3318--3323</ \mathrm{jnl}>$.

$<$ lit68><jnl $>$ S. De, S. Mohanty, S. ${ }^{\wedge}$ K. Nayak, J. Inorg. Organomet. Polym. Mater. 2015, 25, $1332--1344</$ jnl $>$.

$<$ lit69><jnl>K. Balasubramanian, M. Burghard, Anal. Bioanal. Chem. 2006, 385, 452-$468</$ jnl $>$.

$<$ lit70><jnl>K. Besteman, J.-O. Lee, F.^^G. Wiertz, H.^^A. Heering, C. Dekker, Nano Lett. 2003, 3, 727--730</jnl >

$<$ lit71 $><$ jnl $>$ R.^^J. Chen, S. Bangsaruntip, K.^^A. Drouvalakis, N.^^W.^^S. Kam, M. Shim, Y. Li, W. Kim, P.^^J. Utz, H. Dai, Proc. Natl. Acad. Sci. USA 2003, 100, 4984-$4989</$ jnl $>$.

$<$ lit72><jnl >S. Sotiropoulou, N.^^A. Chaniotakis, Anal. Bioanal. Chem. 2003, 375, 103-$105</$ jnl $>$.

$<$ lit73><jnl >J. Wang, M. Musameh, Y. Lin, J. Am. Chem. Soc. 2003, 125, 2408--2409</jnl>. $<$ lit74><jnl>X. Zhao, L. Liu, X. Li, J. Zeng, X. Jia, P. Liu, Langmuir 2014, 30, 10419-$10429</$ jnl $>$. 


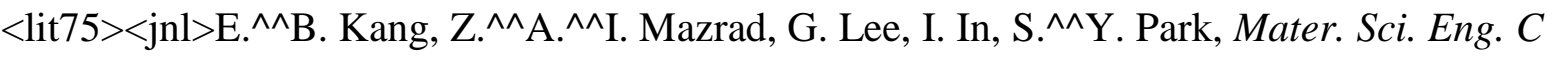
2017, 71, 1064--1071</jnl>.

$<$ lit76><jnl>Y. Sheng, L.-D. Liao, A. Bandla, Y.-H. Liu, J. Yuan, N. Thakor, M.^^C. Tan, Mater. Sci. Eng. C 2017, 70, 340--346</jnl>.

$<$ lit77><jnl>K. Yang, L. Hu, X. Ma, S. Ye, L. Cheng, X. Shi, C. Li, Y. Li, Z. Liu, Adv. Mater. 2012, 24, 1868--1872</jnl>.

$<$ lit78 $><$ jnl $>$ W. ${ }^{\wedge}$ S. Hummers Jr, R.^^E. Offeman, J. Am. Chem. Soc. 1958, 80, 1339-$1339</$ jnl $>$.

$<$ lit79><jnl $>$ M. ${ }^{\wedge}$ J. McAllister, J.-L. Li, D. ${ }^{\wedge}$ H. Adamson, H.^^C. Schniepp, A. ${ }^{\wedge}$ A. Abdala, J. Liu, M. Herrera-Alonso, D.^^L. Milius, R. Car, R.^^K. Prud'homme, Chem. Mater. 2007, 19, 4396--4404</jnl>.

$<$ lit80><jnl>H. ${ }^{\wedge}$ C. Schniepp, J.-L. Li, M. ${ }^{\wedge}$ J. McAllister, H. Sai, M. Herrera-Alonso, D. ${ }^{\wedge} H$. Adamson, R. ${ }^{\wedge}$ K. Prud'homme, R. Car, D.^^A. Saville, I.^^A. Aksay, J. Phys. Chem. B 2006, 110, 8535--8539</jnl >.

$<$ lit81><jnl >S. Stankovich, D.^^A. Dikin, R. ${ }^{\wedge \wedge} D$. Piner, K.^^A. Kohlhaas, A. Kleinhammes, Y. Jia, Y. Wu, S.^^T. Nguyen, R.^^S. Ruoff, Carbon 2007, 45, 1558--1565</jnl>. $<$ lit82><book>W. Gao, in Graphene oxide, Springer, 2015, pp. ${ }^{\wedge} 61--95</$ book> . $<$ lit83><jnl> T. Szabó, O. Berkesi, P. Forgó, K. Josepovits, Y. Sanakis, D. Petridis, I. Dékány, Chem. Mater. 2006, 18, 2740--2749</jnl>.

$<$ lit84><jnl>X. Sun, Z. Liu, K. Welsher, J.^^T. Robinson, A. Goodwin, S. Zaric, H. Dai, Nano Res. 2008, 1, 203--212</jnl> .

$<$ lit85><jnl>C. ${ }^{\wedge}$ H. Lu, H.^^H. Yang, C. ${ }^{\wedge}$ L. Zhu, X. Chen, G. ${ }^{\wedge}$ N. Chen, Angew. Chem. Int. Ed. 2009, 121, 4879--4881</jnl>.

$<$ lit86><jnl>Z. Li, S.^^L. Wong, Mater. Sci. Eng. C 2017, 70, 1095--1106</jnl>. $<$ lit87 ><book>K. Singh, A. Ohlan, S. Dhawan, in Nanocomposites-New Trends and Developments, InTech, 2012</book $>$. 
$<$ lit88 $><j n l>$ V. Barranco, M. Lillo-Rodenas, A. Linares-Solano, A. Oya, F. Pico, J. Ibanez, F. Agullo-Rueda, J. Amarilla, J. Rojo, J. Phys. Chem. C 2010, 114, 10302--10307</jnl>. $<$ lit89><jnl>M. Endo, Y. Kim, T. Hayashi, Y. Fukai, K. Oshida, M. Terrones, T. Yanagisawa, S. Higaki, M. Dresselhaus, Appl. Phys. Lett. 2002, 80, 1267--1269</jnl>. $<$ lit90><jnl>A. ${ }^{\wedge}$ K. ${ }^{\wedge}$ C. Gallegos, M.^^ E. Rincón, J. Power Sources 2006, 162, $743--$ $747</$ jnl $>$.

$<$ lit91><jnl>N.^^C. Hung, I. Anoshkin, E. Rakov, Russ. J. Appl. Chem. 2007, 80, 443-$447</$ jnl $>$.

$<$ lit92><jnl>C.-W. Huang, Y.-T. Wu, C.-C. Hu, Y.-Y. Li, J. Power Sources 2007, 172, 460-$467</$ jnl $>$.

$<$ lit93><jnl>J. Jang, J. Bae, M. Choi, S.-H. Yoon, Carbon 2005, 43, 2730--2736</jnl>.

$<$ lit94><jnl>T. Kim, S. Lim, K. Kwon, S.-H. Hong, W. Qiao, C.^^K. Rhee, S.-H. Yoon, I.

Mochida, Langmuir 2006, 22, 9086--9088</jnl> .

$<$ lit95><jnl >S.^^H. Kim, Y.^^I. Kim, J.^^H. Park, J.^^M. Ko, Int. J. Electrochem. Sci. 2009, 4, 1489--1496</jnl>.

$<$ lit96><jnl>C. Merino, P. Soto, E. Vilaplana-Ortego, J.^^M.^^G. de Salazar, F. Pico, J.^^M. Rojo, Carbon 2005, 43, 551--557</jnl>.

$<$ lit97><jnl > X. Tao, X. Zhang, L. Zhang, J. Cheng, F. Liu, J. Luo, Z. Luo, H. Geise, Carbon 2006, 44, 1425--1428</jnl >.

$<$ lit98><jnl>J. Vera-Agullo, H. Varela-Rizo, J.^^A. Conesa, C. Almansa, C. Merino, I.

Martin-Gullon, Carbon 2007, 45, 2751--2758</jnl>.

$<$ lit99><jnl>S.-H. Yoon, S. Lim, Y. Song, Y. Ota, W. Qiao, A. Tanaka, I. Mochida, Carbon 2004, 42, 1723--1729</jnl >.

$<$ lit100 ><jnl>B. Boskovic, V. Golovko, M. Cantoro, B. Kleinsorge, A. Chuang, C. Ducati, S. Hofmann, J. Robertson, B. Johnson, Carbon 2005, 43, 2643--2648</jnl>. 
$<$ lit101 $><$ jnl $>$ Z. Houweling, V. Verlaan, G. Ten Grotenhuis, R. Schropp, T. Solid. Film. 2009, 517, 3566--3569</jnl>.

$<$ lit102><jnl>D. Hulicova-Jurcakova, X. Li, Z. Zhu, R. De Marco, G.^^Q. Lu, Energy Fuels 2008, 22, 4139--4145</jnl >.

$<$ lit103><jnl>S.-U. Kim, K.-H. Lee, Chem. Phys. Lett. 2004, 400, 253--257</jnl>.

$<$ lit104><jnl>D. Luxembourg, X. Py, A. Didion, R. Gadiou, C. Vix-Guterl, G. Flamant, Microporous Mesoporous Mater. 2007, 98, 123--131</jnl>.

$<$ lit105><jnl >J.^^R. McDonough, J.^^W. Choi, Y. Yang, F. La Mantia, Y. Zhang, Y. Cui, Appl. Phys. Lett. 2009, 95, 243109</jnl>.

$<$ lit106 $><$ jnl $>$ S. Pruneanu, Z. Ali, G. Watson, S.-q. Hu, D. Lupu, A. Biris, L. Olenic, G.

Mihailescu, Part. Sci. Technol. 2006, 24, 311--320</jnl>.

<lit107><jnl>A. Romero, A. Garrido, A. Nieto-Márquez, A.^^R. de la Osa, A. de Lucas,

J.^^L. Valverde, Appl. Catal. A 2007, 319, 246--258</jnl>.

$<$ lit108><jnl>V. Mordkovich, Theor. Found. Chem. Eng. 2003, 37, 429--438</jnl>.

$<$ lit109><jnl>B. Maruyama, K. Alam, SAMPE J. 2002, 38, 59--70</jnl>.

$<$ lit110><jnl>K. Lafdi, W. Fox, M. Matzek, E. Yildiz, J. Nanomater. 2007, 2007</jnl>.

$<$ lit111><jnl>P. Serp, M. Corrias, P. Kalck, Appl. Catal. A 2003, 253, 337--358</jnl>.

$<$ lit112><book>M.^^S. Dresselhaus, M. Endo, in Carbon nanotubes, Springer, 2001, pp. $\wedge^{\wedge} 11--28</$ book>

$<$ lit113><jnl $>$ K. Kostarelos, L. Lacerda, G. Pastorin, W. Wu, S. Wieckowski, J. Luangsivilay,

S. Godefroy, D. Pantarotto, J.-P. Briand, S. Muller, Nat. Nanotechnol. 2007, 2, 108-$113</$ jnl $>$.

$<$ lit114 $><$ jnl $>$ K. Donaldson, R. Aitken, L. Tran, V. Stone, R. Duffin, G. Forrest, A.

Alexander, Toxicol. Sci. 2006, 92, 5--22</jnl>.

$<$ lit115><book>S. Reich, C. Thomsen, J. Maultzsch, Carbon nanotubes: basic concepts and physical properties. Editor, John Wiley \& Sons, 2008</book $>$. 
$<$ lit116><jnl>J. Huang, S. Chen, Z. Ren, Z. Wang, K. Kempa, M. Naughton, G. Chen, M. Dresselhaus, Phys. Rev. Lett. 2007, 98, 185501</jnl>.

$<$ lit117><jnl>R. Saito, M. Fujita, G. Dresselhaus, M. Dresselhaus, Appl. Phys. Lett. 1992, 60, 2204--2206</jnl>.

$<$ lit118><jnl>J.-M. Bonard, H. Kind, T. Stöckli, L.-O. Nilsson, Solid-State Electron. 2001, 45, 893--914</jnl>.

$<$ lit119><jnl>Z. Liu, K. Chen, C. Davis, S. Sherlock, Q. Cao, X. Chen, H. Dai, Can. Res. 2008, 68, 6652--6660</jnl >

$<$ lit120 $><$ jnl $>$ K. Balasubramanian, M. Burghard, Small 2005, 1, 180--192</jnl $>$.

$<$ lit121 ><jnl>Y. Murakami, Y. Miyauchi, S. Chiashi, S. Maruyama, Chem. Phys. Lett. 2003, $374,53--58</$ jnl $>$.

$<$ lit122><jnl>B. Zheng, C. Lu, G. Gu, A. Makarovski, G. Finkelstein, J. Liu, Nano Lett. 2002, $2,895--898<$ junl $>$.

$<$ lit123><jnl>S.^^N. Baker, G. ${ }^{\wedge}$ A. Baker, Angew. Chem. Int. Ed. 2010, 49, 6726--6744;

Angew. Chem. 2010, 122, 6876--6896</jnl>.

$<$ lit124><jnl>C. Ding, A. Zhu, Y. Tian, Accoun. Chem. Res. 2013, 47, 20--30</jnl>.

$<$ lit125><book>V. Kumar, G. Toffoli, F. Rizzolio, in Book Fluorescent carbon nanoparticles in medicine for cancer therapy, ed., ed. by Editor, ACS Publications, City, 2013, Chap. Chapter $</$ book $>$.

$<$ lit126><jnl>S. Ray, A. Saha, N.^^R. Jana, R. Sarkar, J. Phys. Chem. C 2009, 113, 18546-$18551</ \mathrm{jnl}>$.

$<$ lit127><jnl>S.^^A. Chechetka, E. Miyako, Chem. Sel. 2016, 1, 608--611</jnl>. $<$ lit128><jnl>H. Wang, C. Liu, Z. Liu, J. Ren, X. Qu, Small 2018, 14, 1703710</jnl>. $<$ lit129><jnl>F. Khodadadei, S. Safarian, N. Ghanbari, Mater. Sci. Eng. C 2017, 79, 280-$285</$ jnl $>$. 
$<$ lit130><jnl>X. Liu, Y. Zhang, D. Ma, H. Tang, L. Tan, Q. Xie, S. Yao, Colloids Surf. B 2013, 111, 224--231</jnl>.

$<$ lit131 $><$ jnl $>$ K. ${ }^{\wedge}$ A. Zimmermann, D. ${ }^{\wedge}$ L. Inglefield, J. Zhang, H.^^C. Dorn, T.^^E. Long, C.^^G. Rylander, M.^^N. Rylander, J. Nanopart. Res. 2014, 16, 2078</jnl>.

$<$ lit132><jnl>D. Chen, C. Wang, X. Nie, S. Li, R. Li, M. Guan, Z. Liu, C. Chen, C. Wang, C. Shu, Adv. Funct. Mater. 2014, 24, 6621--6628</jnl>.

$<$ lit133><jnl >H. Watanabe, H. Kondo, Y. Okamoto, M. Hiramatsu, M. Sekine, Y. Baba, M.

Hori, Appl. Phys. Lett. 2014, 105, 244105</jnl>.

$<$ lit134 $><$ jnl $>$ R. Taylor, D. ${ }^{\wedge}$ R. Walton, Nature 1993, 363, 685</jnl $>$.

$<$ lit135><jnl>R. Haddon, Philos. Trans. R. Soc. London 1993, 343, 53--62</jnl>.

$<$ lit136><book>K.^^M. Kadish, R.^^S. Ruoff, Fullerenes: chemistry, physics, and

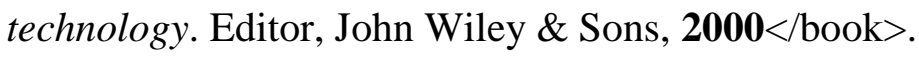

$<$ lit137><book>P.^^W. Fowler, D. Manolopoulos, An atlas of fullerenes. Editor, Courier Corporation, 2006 $</$ book $>$.

$<$ lit138><jnl>Q. Xie, E. Perez-Cordero, L. Echegoyen, J. Am. Chem. Soc. 1992, 114, 3978-$3980</$ jnl $>$.

<lit139><jnl>I. Rašović, Mater. Sci. Technol. 2017, 33, 777--794</jnl>.

$<$ lit140><jnl>G. Churilov, Fullerenes Nanotubes Carbon Nanostruct. 2008, 16, 395-$403</$ jnl $>$.

$<$ lit141 ><jnl>M. Batory, D. Batory, J. Grabarczyk, W. Kaczorowski, B. Kupcewicz, K.

Mitura, T. Nasti, N. Yusuf, P. Niedzielski, J. Nanosci. Nanotechnol. 2012, 12, 9037-$9046</$ jnl $>$.

$<$ lit142><jnl>A. Krueger, J. Mater. Chem. 2008, 18, 1485--1492</jnl>.

$<$ lit143><jnl>A. Krueger, D. Lang, Adv. Funct. Mater. 2012, 22, 890--906</jnl>.

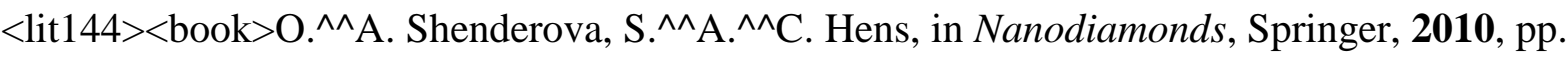
79--116</book>. 
$<$ lit145><other $>$ K. ${ }^{\wedge}$ M. El-Say, 2011</other $>$.

$<$ lit146><jnl>J. Li, Y. Zhu, W. Li, X. Zhang, Y. Peng, Q. Huang, Biomaterials 2010, 31, $8410--8418</ j n l>$.

$<$ lit147>>jnl>K.-K. Liu, W.-W. Zheng, C.-C. Wang, Y.-C. Chiu, C.-L. Cheng, Y.-S. Lo, C.

Chen, J.-I. Chao, Nanotechnology 2010, 21, 315106</jnl>.

$<$ lit148><jnl >Z. Zhang, B. Niu, J. Chen, X. He, X. Bao, J. Zhu, H. Yu, Y. Li, Biomaterials 2014, 35, 4565--4572</jnl >

$<$ lit149><jnl>J. Xiao, X. Duan, Q. Yin, Z. Zhang, H. Yu, Y. Li, Biomaterials 2013, 34, 9648$-9656</ \mathrm{jnl}>$.

$<$ lit150><jnl>Y. Zhu, J. Li, W. Li, Y. Zhang, X. Yang, N. Chen, Y. Sun, Y. Zhao, C. Fan, Q.

Huang, Theranostics 2012, 2, 302</jnl $>$.

$<$ lit151><jnl>B. Guan, F. Zou, J. Zhi, Small 2010, 6, 1514--1519</jnl>.

$<$ lit152><jnl>K. Adach, M. Fijalkowski, G. Gajek, J. Skolimowski, R. Kontek, A. Blaszczyk, Chem.-Biol. Interact. 2016, 254, 156--166</jnl>.

$<$ lit153><jnl>D. Amans, A.-C. Chenus, G. Ledoux, C. Dujardin, C. Reynaud, O.

Sublemontier, K. Masenelli-Varlot, O. Guillois, Diamond Relat. Mater. 2009, 18, 177-$180</ \mathrm{jnl}>$.

$<$ lit154><jnl>I. Kovalenko, D.^^G. Bucknall, G. Yushin, Adv. Funct. Mater. 2010, 20, 3979-$3986</$ jnl $>$.

$<$ lit155><jnl >J.^^K. McDonough, Y. Gogotsi, Electrochem. Soc. Interface 2013, 22, 61-$66</$ jnl $>$.

$<$ lit156><jnl>V.^^N. Mochalin, O. Shenderova, D. Ho, Y. Gogotsi, Nat. Nanotechnol. 2012, $7,11</ \mathrm{jnl}>$.

$<$ lit157><jnl>J. Cebik, J.^^K. McDonough, F. Peerally, R. Medrano, I. Neitzel, Y. Gogotsi,

S. Osswald, Nanotechnology 2013, 24, 205703</jnl>. 
$<$ lit158><jnl>I. Alexandrou, H. Wang, N. Sano, G. Amaratunga, J. Chem. Phys. 2004, 120, $1055--1058</$ jnl $>$.

$<$ lit159><jnl>N. Sano, H. Wang, I. Alexandrou, M. Chhowalla, K. Teo, G. Amaratunga, K. Limura, J. Appl. Phys. 2002, 92, 2783--2788</jnl>.

$<$ lit160><jnl>Y. Yang, X. Liu, X. Guo, H. Wen, B. Xu, J. Nanopart. Res. 2011, 13, 1979-$1986</$ jnl $>$.

$<$ lit161><jnl>L. Dai, Acc. Chem. Res. 2012, 46, 31--42</jnl $>$.

$<$ lit162><jnl>H.^^A. Becerril, J. Mao, Z. Liu, R.^^M. Stoltenberg, Z. Bao, Y. Chen, ACS

Nano 2008, 2, 463--470</jnl >.

$<$ lit163><jnl>S.-S. Li, K.-H. Tu, C.-C. Lin, C.-W. Chen, M. Chhowalla, ACS Nano 2010, 4, $3169--3174</$ jnl $>$.

$<$ lit164><jnl>G. Liu, X. Zhuang, Y. Chen, B. Zhang, J. Zhu, C.-X. Zhu, K.-G. Neoh, E.-T. Kang, Appl. Phys. Lett. 2009, 95, 327</jnl>.

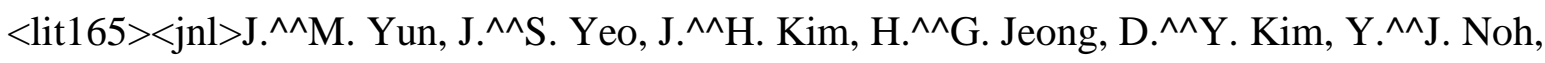

S. ${ }^{\wedge}$ S. Kim, B. ${ }^{\wedge \wedge}$ C. Ku, S. ${ }^{\wedge \wedge}$ I. Na, Adv. Mater. 2011, 23, 4923--4928</jnl>.

$<$ lit166><jnl>E.-K. Choi, I.-Y. Jeon, S.-Y. Bae, H.-J. Lee, H.^^S. Shin, L. Dai, J.-B. Baek, Chem. Commun. 2010, 46, 6320--6322</jnl >.

<lit167><jnl>I.-Y. Jeon, Y.-R. Shin, G.-J. Sohn, H.-J. Choi, S.-Y. Bae, J. Mahmood, S.-M.

Jung, J.-M. Seo, M.-J. Kim, D.^^W. Chang, Proc. Natl. Acad. Sci. USA 2012, 109, $5588--5593</$ jnl $>$.

$<$ lit168><jnl>K.-H. Nam, J. Cho, H. Yeo, Polymer 2017, 10, 29</jnl>.

$<$ lit169><jnl>J. Bai, Y. Liu, X. Jiang, Biomaterials 2014, 35, 5805--5813</jnl>.

$<$ lit170><jnl>N. Aguiló-Aguayo, L. Maurizi, S. Galmarini, M. ${ }^{\wedge}$ G. Ollivier-Beuzelin, G.

Coullerez, E. Bertran, H. Hofmann, Dalton Trans. 2014, 43, 13764--13775</jnl>. $<$ lit171><jnl>S. Xu, Y. Luo, R. Haag, Marcomol. Biosci. 2007, 7, 968--974</jnl>. 
$<$ lit172><jnl>M. Bottini, N. Rosato, N. Bottini, Biomacromolecules 2011, 12, 3381-$3393</$ jnl $>$.

$<$ lit173><jnl>J.^^T. Acquaviva III, C. ${ }^{\wedge}$ F. Bahavar, F. Zhou, X. Li, E. ${ }^{\wedge}$ W. Howard, L. ${ }^{\wedge}$ C. Bullen, R.^^P. Silvy, W.^^R. Chen, J. Inno. Opt. Health Sci. 2015, 8, 1550036</jnl>. $<$ lit174><jnl>H. Dumortier, S. Lacotte, G. Pastorin, R. Marega, W. Wu, D. Bonifazi, J.-P.

Briand, M. Prato, S. Muller, A. Bianco, Nano Lett. 2006, 6, 1522--1528</jnl>. $<$ lit175 $><$ jnl $>$ N. ${ }^{\wedge} M$ M. Bardhan, P. ${ }^{\wedge}$ V. Kumar, Z. Li, H. ${ }^{\wedge}$ L. Ploegh, J. ${ }^{\wedge}$ C. Grossman, A.^^M. Belcher, G.-Y. Chen, ACS Nano 2017, 11, 1548--1558</jnl>. $<$ lit176><jnl>H. Liu, T. Ye, C. Mao, Angew. Chem. Int. Ed. 2007, 46, 6473--6475; Angew. Chem. 2007, 119, 6593--6595</jnl $>$. $<$ lit177><jnl >S. Song, F. Zhou, R.^^E. Nordquist, R. Carubelli, H. Liu, W.^^R. Chen, Immunopharmacol. Immunotoxicol. 2009, 31, 202--208</jnl>.

$<$ lit178><jnl $>$ W.^^R. Chen, H. Liu, J.^^A. Nordquist, R.^^E. Nordquist, Laser. Med. Sci. 2000, $15,43--48</$ jnl $>$.

$<$ lit179><jnl>F. Zhou, X. Li, S. Song, J.^^T. Acquaviva^^III, R. ${ }^{\wedge \wedge}$ F. Wolf, E. ${ }^{\wedge}$ W. Howard, W.^^R. Chen, J. Innov. Opt. Health Sci. 2013, 6, 1350039</jnl>. $<$ lit180><jnl >C. Li, K. Yang, Y. Zhang, H. Tang, F. Yan, L. Tan, Q. Xie, S. Yao, Acta Biomater. 2011, 7, 3070--3077</jnl >. $<$ lit181 ><jnl >R. Andrews, D. Jacques, D. Qian, T. Rantell, Acc. Chem. Res. 2002, 35, 1008-$1017</$ jnl $>$. $<$ lit182><jnl>J.^^L. Bahr, J.^^M. Tour, J. Mater. Chem. 2002, 12, 1952--1958</jnl>. $<$ lit183><jnl>S. Banerjee, M.^^G. Kahn, S.^^S. Wong, Chem. A Eur. J. 2003, 9, 1898-$1908</$ jnl $>$. $<$ lit184><jnl>S. Banerjee, T. Hemraj-Benny, S.^^S. Wong, Adv. Mater. 2005, 17, 17-$29</$ jnl $>$. $<$ lit185><jnl>C.^^A. Dyke, J.^^M. Tour, Chem. A Eur. J. 2004, 10, 812--817</jnl>. 
$<$ lit186 $><$ jnl $>$ A. Hirsch, Nat. Mater. 2010, 9, 868--871</jnl $>$.

$<$ lit187><jnl>A. Hirsch, Angew. Chem. Int. Ed. 2002, 41, 1853--1859; Angew. Chem. 2002, 114, 1933--1939</jnl>.

$<$ lit188><jnl>Y.-J. Lu, K.-C. Wei, C.-C.^^M. Ma, S.-Y. Yang, J.-P. Chen, Colloid. Surf. B Biointerf. 2012, 89, 1--9</jnl >.

$<$ lit189 $><$ jnl $>$ D. Tasis, N. Tagmatarchis, A. Bianco, M. Prato, Chem. Rev. 2006, 106, 1105-$1136</$ jnl $>$.

$<$ lit190><book>A. Hirsch, O. Vostrowsky, in Functional molecular nanostructures, Springer, 2005, pp.^^193--237</book>.

$<$ lit191><jnl>J. Chen, M.^^J. Dyer, M.-F. Yu, J. Am. Chem. Soc. 2001, 123, 6201-$6202</$ jnl $>$.

$<$ lit192><jnl>G. Chambers, C. Carroll, G. ${ }^{\wedge}$ F. Farrell, A. ${ }^{\wedge}$ B. Dalton, M. McNamara, M. in het Panhuis, H.^^J. Byrne, Nano Lett. 2003, 3, 843--846</jnl>.

$<$ lit193><jnl>A. Cassez, A. Ponchel, F. Hapiot, E. Monflier, Org. Lett. 2006, 8, 4823-$4826</$ jnl $>$.

$<$ lit194><jnl> T. Loftsson, P. Jarho, M. Masson, T. Järvinen, Expert Opin. Drug Delivery 2005, 2, 335--351</jnl >

$<$ lit195><jnl>A. Denicourt-Nowicki, A. Roucoux, F. Wyrwalski, N. Kania, E. Monflier, A.

Ponchel, Chem. A Eur. J. 2008, 14, 8090--8093</jnl>.

$<$ lit196><jnl>I. Abe, T. Fukuhara, N. Kawasaki, M. Hitomi, Y. Kera, J. Colloid Interface Sci. 2000, 229, 615--619</jnl>.

$<$ lit197><jnl>J. Szejtli, Chem. Rev. 1998, 98, 1743--1754</jnl>.

<lit198><jnl>T. Da Ros, M. Prato, Chem. Commun. 1999, 663--669</jnl>.

$<$ lit199><jnl>S. Kraszewski, M. Tarek, C. Ramseyer, ACS Nano 2011, 5, 8571--8578</jnl>. $<$ lit200><jnl>D. Pantarotto, C.^^D. Partidos, R. Graff, J. Hoebeke, J.-P. Briand, M. Prato, A.

Bianco, J. Am. Chem. Soc. 2003, 125, 6160--6164</jnl>. 
$<$ lit201><jnl>R. Ruoff, D. ${ }^{\wedge}$ S. Tse, R. Malhotra, D. ${ }^{\wedge}$ C. Lorents, J. Phys. Chem. 1993, 97, $3379--3383</$ jnl $>$.

$<$ lit202><jnl>N. Sivaraman, R. Dhamodaran, I. Kaliappan, T. Srinivasan, P.^^V. Rao, C.

Mathews, J. Org. Chem. 1992, 57, 6077--6079</jnl>.

<lit203><jnl>I. Matai, A. Sachdev, P. Gopinath, ACS Appl. Mater. Interfaces 2015, 7, 11423$-11435</$ jnl $>$.

$<$ lit204><jnl>S. Ghosh, S. Dutta, E. Gomes, D. Carroll, R. D’Agostino Jr, J. Olson, M.

Guthold, W.^^H. Gmeiner, ACS Nano 2009, 3, 2667--2673</jnl>.

$<$ lit205><jnl >N. Huang, H. Wang, J. Zhao, H. Lui, M. Korbelik, H. Zeng, Lasers Surg. Med. 2010, 42, 798--808</jnl >.

$<$ lit206><jnl >X. Liu, H. Tao, K. Yang, S. Zhang, S.-T. Lee, Z. Liu, Biomaterials 2011, 32, $144--151</ j n l>$.

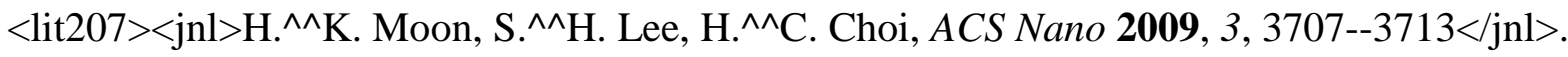
$<$ lit208><jnl>S. Shen, J. Ren, X. Zhu, Z. Pang, X. Lu, C. Deng, R. Zhang, X. Jiang, J. Mater. Chem. B 2013, 1, 1939--1946</jnl>.

$<$ lit209><jnl>C.-H. Wang, Y.-J. Huang, C.-W. Chang, W.-M. Hsu, C.-A. Peng, Nanotechnology 2009, 20, 315101</jnl>.

$<$ lit210 $><$ other $>$ S. Anand, N. Atanaskova, C. Wilson, T. Hasan, E. Maytin, in Book Enhancement of protoporphyrin IX and suppression of ferrochelatase levels by Vitamin $D$ in tumor models of nonmelanoma skin cancer: implications for tumor response to photodynamic therapy, ed., ed. by Editor, NATURE PUBLISHING GROUP 75

VARICK ST, 9TH FLR, NEW YORK, NY 10013--1917 USA, City, 2010, Vol. 130, Chap. Chapter, pp. S137--S137</other>.

$<$ lit211><jnl>S. Cui, H. Chen, H. Zhu, J. Tian, X. Chi, Z. Qian, S. Achilefu, Y. Gu, J. Mater. Chem. 2012, 22, 4861--4873</jnl $>$.

$<$ lit212><jnl>B. Ungun, R.^^K. Prud’homme, S.^^J. Budijono, J. Shan, S.^^F. Lim, Y. Ju, R. Austin, Optic. Exp. 2009, 17, 80--86</jnl>. 
$<$ lit213><jnl>K. Minami, K. Okamoto, D. Kent, K. Harano, E. Noiri, E. Nakamura, Sci. Rep. 2014, 4, 4916</jnl $>$.

$<$ lit214><jnl >F. Yin, K. Hu, Y. Chen, M. Yu, D. Wang, Q. Wang, K.-T. Yong, F. Lu, Y. Liang, Z. Li, Theranostics 2017, 7, 1133</jnl>.

$<$ lit215><jnl>K.^^H. Son, J.^^H. Hong, J.^^W. Lee, Int. J. Nanomed. 2016, 11, 5163</jnl>. $<$ lit216><book>A. Elhissi, W. Ahmed, V. Dhanak, K. Subramani, in Emerging

Nanotechnologies in Dentistry, Elsevier, 2012, pp. ${ }^{\wedge} 347--363</$ book>.

$<$ lit217><jnl >S. Prakash, M. Malhotra, W. Shao, C. Tomaro-Duchesneau, S. Abbasi, Adv. Drug Delivery Rev. 2011, 63, 1340--1351</jnl>.

$<$ lit218><jnl>B. Behnam, W.^^T. Shier, A.^^H. Nia, K. Abnous, M. Ramezani, Int. J.

Pharm. 2013, 454, 204--215</jnl $>$.

$<$ lit219><jnl>L. Gao, L. Nie, T. Wang, Y. Qin, Z. Guo, D. Yang, X. Yan, ChemBioChem 2006, 7, 239--242</jnl $>$.

$<$ lit220 ><jnl>A. Karmakar, S.^^M. Bratton, E. Dervishi, A. Ghosh, M. Mahmood, Y. Xu,

L. ${ }^{\wedge}$ M. Saeed, T. Mustafa, D. Casciano, A. Radominska-Pandya, Int. J. Nanomed. 2011, $6,1045</$ jnl $>$.

$<$ lit221><jnl>Y. Liu, D.^^C. Wu, W.^^D. Zhang, X. Jiang, C. ${ }^{\wedge}$ B. He, T. ${ }^{\wedge}$ S. Chung, S.^^H.

Goh, K. ${ }^{\wedge} W$. Leong, Angew. Chem. Int. Ed. 2005, 117, 4860--4863</jnl>. $<$ lit222 ><jnl $>$ W. Cheung, F. Pontoriero, O. Taratula, A.^^M. Chen, H. He, Adv. Drug

Delivery Rev. 2010, 62, 633--649</jnl>.

$<$ lit223><jnl>D. Pantarotto, R. Singh, D. McCarthy, M. Erhardt, J.^^P. Briand, M. Prato, K.

Kostarelos, A. Bianco, Angew. Chem. Int. Ed. 2004, 116, 5354--5358</jnl>.

$<$ lit224><jnl>R. Singh, D. Pantarotto, D. McCarthy, O. Chaloin, J. Hoebeke, C.^^D. Partidos, J.-P. Briand, M. Prato, A. Bianco, K. Kostarelos, J. Am. Chem. Soc. 2005, 127, 4388-$4396</$ jnl $>$. 
$<$ lit225><jnl>G. Bartholomeusz, P. Cherukuri, J. Kingston, L. Cognet, R. Lemos, T.^^K. Leeuw, L. Gumbiner-Russo, R.^^B. Weisman, G. Powis, Nano Res. 2009, 2, 279-$291</$ jnl $>$.

$<$ lit226><jnl>J.^^E. Podesta, K. ${ }^{\wedge \wedge}$ T. Al-Jamal, M. ${ }^{\wedge \wedge}$ A. Herrero, B. Tian, H. Ali-Boucetta, V.

Hegde, A. Bianco, M. Prato, K. Kostarelos, Small 2009, 5, 1176--1185</jnl>.

$<$ lit227><jnl >A. ${ }^{\wedge}$ K. Varkouhi, S. Foillard, T. Lammers, R.^^M. Schiffelers, E. Doris,

W.^^E. Hennink, G. Storm, Int. J. Pharmacogn. 2011, 416, 419--425</jnl>.

$<$ lit228 $><$ jnl $>$ X. Wang, L. Cao, S.^^T. Yang, F. Lu, M.^^J. Meziani, L. Tian, K. ${ }^{\wedge}$ W. Sun,

M.^^A. Bloodgood, Y.^^P. Sun, Angew. Chem. Int. Ed. 2010, 122, 5438--5442</jnl>.

<lit229><jnl>P. Röthlisberger, C. Gasse, M. Hollenstein, Int. J. Mol. Sci. 2017, 18,

$2430</ \mathrm{jnl}>$.

$<$ lit230><jnl > X. Zhang, J. Yin, C. Peng, W. Hu, Z. Zhu, W. Li, C. Fan, Q. Huang, Carbon 2011, 49, 986--995</jnl>.

$<$ lit231><jnl $>$ W. ${ }^{\wedge}$ B. Liechty, D. ${ }^{\wedge}$ R. Kryscio, B. ${ }^{\wedge}$ V. Slaughter, N.^^A. Peppas, Ann. Rev.

Chem. Biomol. Eng. 2010, 1, 149--173</jnl>.

$<$ lit232><jnl>A. Srivastava, T. Yadav, S. Sharma, A. Nayak, A.^^A. Kumari, N. Mishra, $J$.

Biosci. 2015, 4, 69</jnl>.

$<$ lit233><jnl>O. Pillai, R. Panchagnula, Curr. Opin. Chem. Biol. 2001, 5, 447--451</jnl>. $<$ lit234><jnl>L.^^W. Zhang, L. Zeng, A.^^R. Barron, N.^^A. Monteiro-Riviere, Int. J.

Toxicol. 2007, 26, 103--113</jnl $>$.

$<$ lit235><jnl>D. Iannazzo, A. Pistone, M. Salamò, S. Galvagno, R. Romeo, S.^^ ${ }^{\wedge}$. Giofré, C.

Branca, G. Visalli, A. Di Pietro, Int. J. Pharmacogn. 2017, 518, 185--192</jnl>.

$<$ lit236><jnl >J.^^M. Tan, G. Karthivashan, P. Arulselvan, S. Fakurazi, M.^^Z. Hussein, Drug

Des. Dev. Ther. 2014, 8, 2333</jnl >.

$<$ lit237><jnl>M. Joshi, P. Kumar, R. Kumar, G. Sharma, B. Singh, O.^^P. Katare, K. Raza, Mater. Sci. Eng. C 2017, 75, 1376--1388</jnl>. 
$<$ lit238><jnl>F. Yang, C. Jin, D. Yang, Y. Jiang, J. Li, Y. Di, J. Hu, C. Wang, Q. Ni, D. Fu, Eur. J. Cancer 2011, 47, 1873--1882</jnl>.

$<$ lit239><jnl>Y. Guo, D. Shi, H. Cho, Z. Dong, A. Kulkarni, G. ${ }^{\wedge}$ M. Pauletti, W. Wang, J.

Lian, W. Liu, L. Ren, Adv. Mater. 2008, 18, 2489--2497</jnl>.

$<$ lit240><jnl>L. Cao, Y. Liang, F. Zhao, X. Zhao, Z. Chen, J. Biomed. Nanotechnol. 2016, $12,1312--1322</ \mathrm{jnl}>$.

$<$ lit241><jnl>A. Guven, G. ${ }^{\wedge} J$. Villares, S. ${ }^{\wedge}$ G. Hilsenbeck, A. Lewis, J. ${ }^{\wedge}$ D. Landua, L. ${ }^{\wedge}$ E.

Dobrolecki, L.^^J. Wilson, M.^^T. Lewis, Acta Biomater. 2017, 58, 466--478</jnl>.

$<$ lit242><jnl >X. Zhang, L. Meng, Q. Lu, Z. Fei, P.^^J. Dyson, Biomaterials 2009, 30, 6041-$6047</$ jnl $>$.

$<$ lit243><jnl>T. Nakanishi, S. Fukushima, K. Okamoto, M. Suzuki, Y. Matsumura, M.

Yokoyama, T. Okano, Y. Sakurai, K. Kataoka, J. Controlled Release 2001, 74, 295-$302</$ jnl $>$.

$<$ lit244><jnl>J.-H. Kim, Y.-S. Kim, K. Park, S. Lee, H.^^Y. Nam, K.^^H. Min, H.^^G. Jo, J.^^H. Park, K. Choi, S.^^Y. Jeong, J. Controlled Release 2008, 127, 41--49</jnl>.

$<$ lit245 ><jnl >T. Okuda, S. Kawakami, N. Akimoto, T. Niidome, F. Yamashita, M. Hashida, J. Controlled Release 2006, 116, 330--336</jnl> .

$<$ lit246><jnl >R. Satchi-Fainaro, M. Puder, J.^^W. Davies, H.^^T. Tran, D.^^A. Sampson,

A. ${ }^{\wedge}$ K. Greene, G. Corfas, J. Folkman, Nat. Med. 2004, 10, 255</jnl>.

$<$ lit247><jnl>S. Bayda, M. Hadla, S. Palazzolo, V. Kumar, I. Caligiuri, E. Ambrosi, E.

Pontoglio, M. Agostini, T. Tuccinardi, A. Benedetti, J. Controlled Release 2017, 248, $144--152</$ jnl $>$.

$<$ lit248><jnl>T.-W. Kim, P.-W. Chung, I. ${ }^{\wedge}$ I. Slowing, M. Tsunoda, E. ${ }^{\wedge}$ S. Yeung, V. ${ }^{\wedge}$ S.-

Y. Lin, Nano Lett. 2008, 8, 3724--3727</jnl>.

$<$ lit249><jnl>J. Gu, S. Su, Y. Li, Q. He, J. Shi, Chem. Commun. 2011, 47, 2101--2103</jnl>. 
$<$ lit250><jnl>A. Itatahine, Y.^^A. Mehdi, M. Fizir, M. Qi, P. Dramou, H. He, New J. Chem. $2018</$ jnl $>$.

$<$ lit251><jnl>N.^^G. Sahoo, H. Bao, Y. Pan, M. Pal, M. Kakran, H.^^K.^^F. Cheng, L. Li, L.^^P. Tan, Chem. Commun. 2011, 47, 5235--5237</jnl>.

$<$ lit252><jnl >S. Jiang, M.^^K. Gnanasammandhan, Y. Zhang, J. Royal Soc. Interf. 2010, 7, 3$-18</ \mathrm{jnl}>$.

$<$ lit253><jnl>J. Fang, H. Nakamura, H. Maeda, Adv. Drug Delivery Rev. 2011, 63, 136-$151</$ jnl $>$.

$<$ lit254><jnl>T.^^M. Allen, P.^^R. Cullis, Science 2004, 303, 1818--1822</jnl . $<$ lit255 $><$ jnl $>$ H. ${ }^{\wedge}$ A. Edens, B. ${ }^{\wedge}$ P. Levi, D. ${ }^{\wedge}$ L. Jaye, S. Walsh, T. ${ }^{\wedge \wedge}$ A. Reaves, J.^^R.

Turner, A. Nusrat, C. ${ }^{\wedge}$ A. Parkos, J. Immunol. 2002, 169, 476--486</jnl>. <lit256><jnl>G. Sledge, K. Miller, Eur. J. Cancer 2003, 39, 1668--1675</jnl>. $<$ lit257><jnl >J.^^E. Fischer, Acc. Chem. Res. 2002, 35, 1079--1086</jnl . $<$ lit258><jnl>P. Lockman, R. Mumper, M. Khan, D. Allen, Drug Dev. Ind. Pharm. 2002, 28, $1--13</$ jnl $>$.

$<$ lit259><jnl>K. Avgoustakis, A. Beletsi, Z. Panagi, P. Klepetsanis, A. Karydas, D.

Ithakissios, J. Controlled Release 2002, 79, 123--135</jnl>.

$<$ lit260 ><jnl>A. Beletsi, L. Leontiadis, P. Klepetsanis, D. Ithakissios, K. Avgoustakis, Int. J. Pharm. 1999, 182, 187--197</jnl>.

$<$ lit261 ><jnl>K. Greish, J. Fang, T. Inutsuka, A. Nagamitsu, H. Maeda, Clin. Pharmacokinet. 2003, 42, 1089--1105</jnl > .

$<$ lit262><jnl>A. Nagamitsu, K. Greish, H. Maeda, J. Clin. Oncol. 2009, 39, 756--766</jnl>. $<$ lit263><jnl>A.^^K. Geim, K.^^S. Novoselov, Nat. Mater. 2007, 6, 183--191</jnl>. $<$ lit264><jnl>C. Liu, P. Zhang, X. Zhai, F. Tian, W. Li, J. Yang, Y. Liu, H. Wang, W. Wang, W. Liu, Biomaterials 2012, 33, 3604--3613</jnl $>$. 
$<$ lit265><jnl>J.-P. Tessonnier, D. Rosenthal, T.^^W. Hansen, C. Hess, M. ${ }^{\wedge}$ E. Schuster, R. Blume, F. Girgsdies, N. Pfänder, O. Timpe, D.^^S. Su, Carbon 2009, 47, 1779-$1798</$ jnl $>$.

$<$ lit266><book>P. Mukhopadhyay, R.^^K. Gupta, Graphite, Graphene, and their polymer nanocomposites. Editor, CRC Press, 2012</book>.

$<$ lit267><book>E. Beyou, S. Akbar, P. Chaumont, P. Cassagnau, in Syntheses and Applications of Carbon Nanotubes and Their Composites, InTech, 2013</book>. $<$ lit268><jnl >D. Boukhvalov, M. Katsnelson, J. Phys. Condens. Matter 2009, 21, $344205</$ jnl $>$.

$<$ lit269><jnl>M. Alvaro, C. Aprile, P. Atienzar, H. Garcia, J. Phys. Chem. B 2005, 109, 7692--7697</jnl >.

$<$ lit270><jnl >R. Barthos, D. Méhn, A. Demortier, N. Pierard, Y. Morciaux, G. Demortier, A. Fonseca, J. Nagy, Carbon 2005, 43, 321--325</jnl>.

$<$ lit271><jnl>K. Bradley, M. Briman, A. Star, G. Grüner, Nano Lett. 2004, 4, 253--256</jnl>. $<$ lit272><jnl>L. Cai, J.^^L. Bahr, Y. Yao, J.^^M. Tour, Chem. Mater. 2002, 14, 4235-$4241</$ jnl $>$.

$<$ lit273><jnl>J. Cui, M. Burghard, K. Kern, Nano Lett. 2003, 3, 613--615</jnl>.

$<$ lit274><jnl >V. Datsyuk, C. Guerret-Piécourt, S. Dagréou, L. Billon, J.-C. Dupin, E. Flahaut, A. Peigney, C. Laurent, Carbon 2005, 43, 873--876</jnl >.

$<$ lit275><jnl>F. Du, J.^^E. Fischer, K. ${ }^{\wedge}$ I. Winey, J. Polym. Sci. Part B 2003, 41, 3333-$3338</$ jnl $>$.

$<$ lit276><jnl >P. Fournet, J. Coleman, B. Lahr, A. Drury, W. Blau, D. O’Brien, H.-H.

Hörhold, J. Appl. Phys. 2001, 90, 969--975</jnl>.

$<$ lit277><jnl>V. Georgakilas, D. Gournis, M.^^A. Karakassides, A. Bakandritsos, D. Petridis, Carbon 2004, 42, 865--870</jnl $>$. 
$<$ lit278><jnl>R.^^A. Graff, J.^^P. Swanson, P.^^W. Barone, S. Baik, D.^^A. Heller, M.^^S. Strano, Adv. Mater. 2005, 17, 980--984</jnl>.

$<$ lit279><jnl>M. Hamon, H. Hui, P. Bhowmik, H. Itkis, R. Haddon, Appl. Phys. A 2002, 74, $333--338</$ jnl $>$.

$<$ lit280><jnl>S.^^B. Hočevar, J. Wang, R.^^P. Deo, M. Musameh, B. Ogorevc,

Electroanalysis 2005, 17, 417--422</jnl >.

$<$ lit281><jnl>Q. Chen, L. Dai, M. Gao, S. Huang, A. Mau, J. Phys. Chem. B 2001, 105, 618-$622</ \mathrm{jnl}>$.

$<$ lit282><jnl>K. Kamarás, M. Itkis, H. Hu, B. Zhao, R. Haddon, Science 2003, 301, 1501-$1501</$ jnl $>$.

$<$ lit283><jnl>A. Koshio, M. Yudasaka, M. Zhang, S. Iijima, Nano Lett. 2001, 1, 361-$363</$ jnl $>$.

$<$ lit284><jnl>R. ${ }^{\wedge}$ B. Martin, L. Qu, Y. Lin, B. ${ }^{\wedge \wedge}$ A. Harruff, C.^^E. Bunker, J.^^R. Gord,

L.^^F. Allard, Y.-P. Sun, J. Phys. Chem. B 2004, 108, 11447--11453</jnl>.

$<$ lit285><jnl >S. Pekker, J.-P. Salvetat, E. Jakab, J.-M. Bonard, L. Forro, J. Phys. Chem. B

2001, 105, 7938--7943</jnl>.

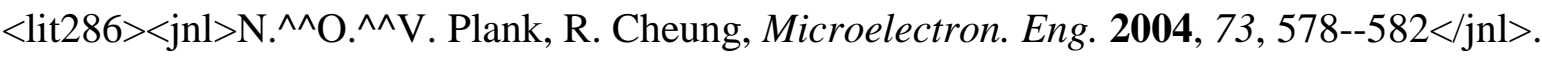

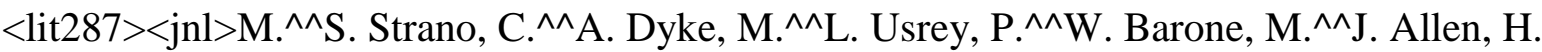

Shan, C. Kittrell, R.^^H. Hauge, J.^^M. Tour, R.^^E. Smalley, Science 2003, 301, $1519--1522</$ jnl $>$.

$<$ lit288 $><j n l>N$. Tagmatarchis, V. Georgakilas, M. Prato, H. Shinohara, Chem. Commun.

2002, 2010--2011</jnl>.

$<$ lit289><jnl>E. Unger, A. Graham, F. Kreupl, M. Liebau, W. Hoenlein, Curr. Appl. Phys. 2002, 2, 107--111</jnl >.

$<$ lit290><jnl>C. Velasco-Santos, A. Martinez-Hernandez, V. Castano, Compos. Interfaces 2005, 11, 567--586</jnl >. 
$<$ lit291><jnl >T. Kuila, S. Bose, A. ${ }^{\wedge}$ K. Mishra, P. Khanra, N.^^H. Kim, J.^^H. Lee, Prog. Mater. Sci. 2012, 57, 1061--1105</jnl>.

$<$ lit292><jnl >H. Touhara, F. Okino, Carbon 2000, 38, 241--267</jnl >.

$<$ lit293 $><$ jnl $>$ N.^^F. Yudanov, A.^^V. Okotrub, Y.^^V. Shubin, L.^^I. Yudanova, L. ${ }^{\wedge} G$.

Bulusheva, A.^^L. Chuvilin, J.-M. Bonard, Chem. Mater. 2002, 14, 1472--1476</jnl>.

$<$ lit294><jnl >H. Touhara, J. Inahara, T. Mizuno, Y. Yokoyama, S. Okanao, K. Yanagiuch, I.

Mukopadhyay, S. Kawasaki, F. Okino, H. Shirai, J. Flur. Chem. 2002, 114, 181-$188</$ jnl $>$.

$<$ lit295><jnl>S. Kawasaki, K. Komatsu, F. Okino, H. Touhara, H. Kataura, Phys. Chem.

Chem. Phys. 2004, 6, 1769--1772</jnl $>$.

$<$ lit296><jnl>N. Lebedev, I. Zaporotskova, L. Chernozatonskii, Int. J. Quantum Chem. 2004, $100,548--558</ \mathrm{jnl}>$.

$<$ lit297 $><$ jnl $>$ M.^^.$^{\wedge}$. Shofner, V.^^N. Khabashesku, E.^^V. Barrera, Chem. Mater. 2006, 18, 906--913</jnl> .

$<$ lit298><jnl>J.-F. Colomer, R. Marega, H. Traboulsi, M. Meneghetti, G. Van Tendeloo, D.

Bonifazi, Chem. Mater. 2009, 21, 4747--4749</jnl>.

$<$ lit299><jnl>J.^^L. Stevens, A.^^Y. Huang, H. Peng, I. ${ }^{\wedge \wedge}$ W. Chiang, V. ${ }^{\wedge}$ N. Khabashesku, J.^^L. Margrave, Nano Lett. 2003, 3, 331--336</jnl> .

$<$ lit300 $><$ jnl $>$ B. ${ }^{\wedge}$ N. Khare, M. Meyyappan, J. Kralj, P. Wilhite, M. Sisay, H. Imanaka, J.

Koehne, C.^^W. Baushchlicher Jr, Appl. Phys. Lett. 2002, 81, 5237--5239</jnl>.

$<$ lit301 ><jnl>B. Khare, M. Meyyappan, M.^^^H. Moore, P. Wilhite, H. Imanaka, B. Chen,

Nano Lett. 2003, 3, 643--646</jnl> .

$<$ lit302><jnl>B.^^N. Khare, M. Meyyappan, A.^^M. Cassell, C.^^V. Nguyen, J. Han, Nano

Lett. 2002, 2, 73--77</jnl>.

$<$ lit303><jnl>K.^^S. Kim, D.^^J. Bae, J.^^R. Kim, K.^^A. Park, S.^^C. Lim, J.^^J. Kim,

W. ${ }^{\wedge}$ B. Choi, C.^^Y. Park, Y.^^H. Lee, Adv. Mater. 2002, 14, 1818--1821</jnl>. 
$<$ lit304><jnl>R. Li, Z. Shang, G. Wang, Y. Pan, X. Zhao, J. Mol. Struct. 2003, 635, 203-$210</ \mathrm{jnl}>$.

$<$ lit305><book>F. Gu, R. Langer, O. ${ }^{\wedge}$ C. Farokhzad, in Micro and Nano Technologies in Bioanalysis, Springer, 2009, pp.^^589--598</book>.

$<$ lit306><jnl>M.^^J. O'Connell, P. Boul, L. ${ }^{\wedge}$ M. Ericson, C. Huffman, Y. Wang, E. Haroz, C.

Kuper, J. Tour, K.^^D. Ausman, R.^^E. Smalley, Chem. Phys. Lett. 2001, 342, 265-$271</ \mathrm{jnl}>$.

$<$ lit307><jnl $>$ A. Star, Y. Liu, K. Grant, L. Ridvan, J.^^F. Stoddart, D.^^W. Steuerman,

M.^^R. Diehl, A. Boukai, J.^^R. Heath, Macromolecules 2003, 36, 553--560</jnl>. $<$ lit308><jnl>A. Star, J.^^F. Stoddart, D. Steuerman, M. Diehl, A. Boukai, E.^^W. Wong, X.

Yang, S.^^W. Chung, H. Choi, J.^^R. Heath, Angew. Chem. Int. Ed. 2001, 40, 1721-1725; Angew. Chem. 2001, 113, 1771--1775</jnl >.

$<$ lit309><jnl>D. ${ }^{\wedge}$ W. Steuerman, A. Star, R. Narizzano, H. Choi, R.^^S. Ries, C. Nicolini,

J.^^F. Stoddart, J.^^R. Heath, J. Phys. Chem. B 2002, 106, 3124--3130</jnl>.

$<$ lit310 > jnl >A. Zhu, Z. Shi, J. Jin, G. Li, J. Jiang, Journal of Macromolecular Science, Part B 2012, 51, 2183--2190</jnl >.

$<$ lit311 ><jnl>A.^^D. Wong, M. Ye, M. ${ }^{\wedge}$ B. Ulmschneider, P. ${ }^{\wedge}$ C. Searson, PLoS One 2015, $10, \mathrm{e} 0123461</ \mathrm{jnl}>$.

$<$ lit312 ><jnl>L. Bannon-Peppas, J. Blanchette, Adv. Drug Delivery Rev. 2004, 56, 1649-$1659</ \mathrm{jnl}>$.

$<$ lit313><jnl>C. Iancu, L. Mocan, Int. J. Nanomed. 2011, 6, 1675</jnl >.

Figure $^{\wedge \wedge} 1$ The most common allotropes of carbon. Elemental carbon exists in two natural allotropes, graphite and diamond, which consist of extended networks of $\mathrm{sp}^{2}$ - and $\mathrm{sp}^{3}$ hybridized carbon atoms. There are also known synthetic carbon allotropes -- fullerenes, nanotubes and graphene. ${ }^{[186]}$ Graphene is a 2D building material for allotropes of carbon nanomaterials. It can be wrapped up into OD buckyball, rolled into a 1D nanotube, or stacked into 3D graphite. ${ }^{[263]} \mathrm{sp}^{2}$-carbon nanomaterials include fullerene, carbon nanotubes, and 
graphene, while to $\mathrm{sp}^{3}$-carbon nanomaterials belong nanodiamonds. ${ }^{[264]}$ Adapted from Singh et $^{\wedge \wedge}$ al. $^{[87]}$

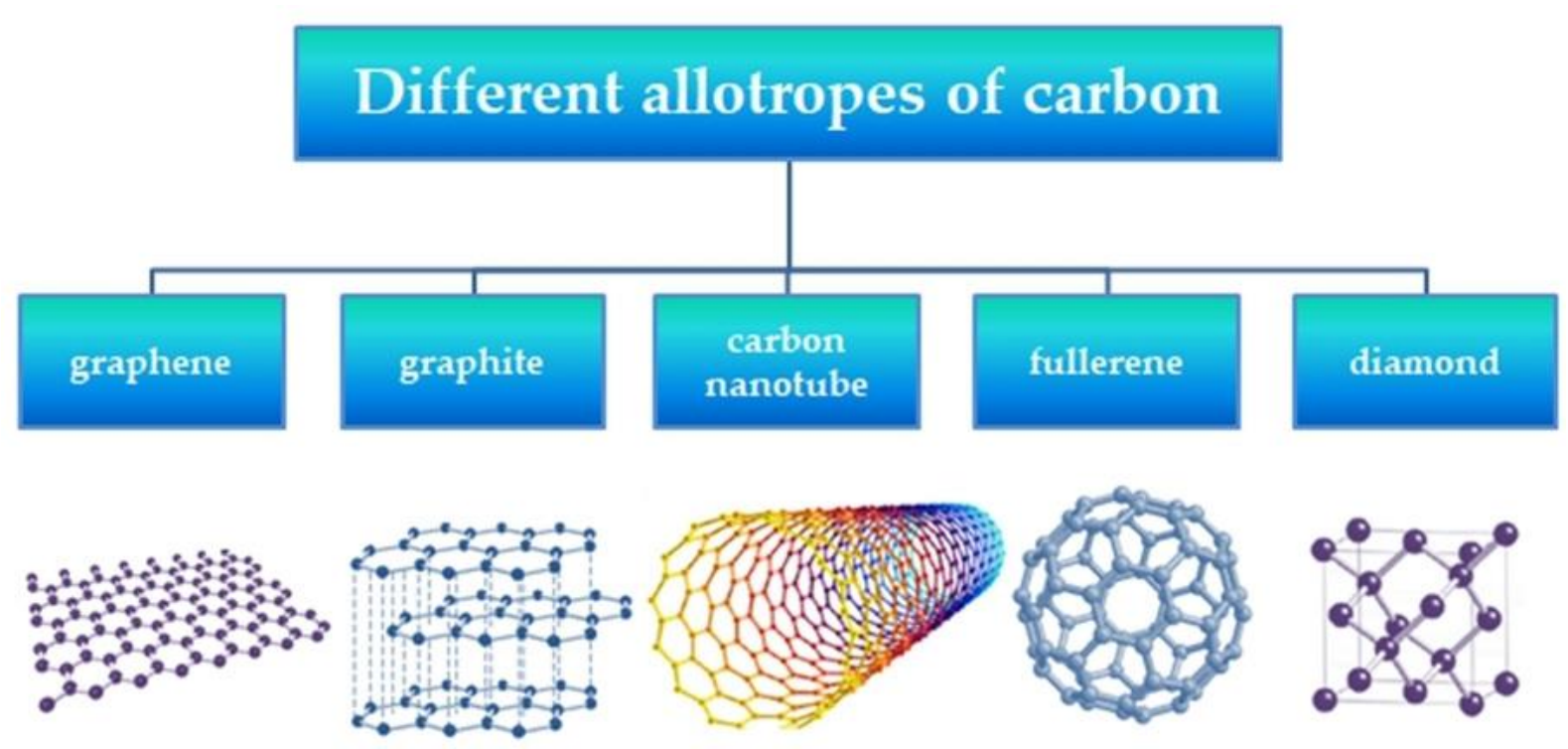

Figure $^{\wedge} 2$ Schematic representation of CNFs and CNTs. Despite the different morphological structure, hollow CNF and MWCNT can be included under the term MWCNTs. Furthermore, according to the definition of Dresselhaus and Endo,${ }^{[112]}$ only the last one can be called MWCNT. Adapted from. ${ }^{[265]}$ 


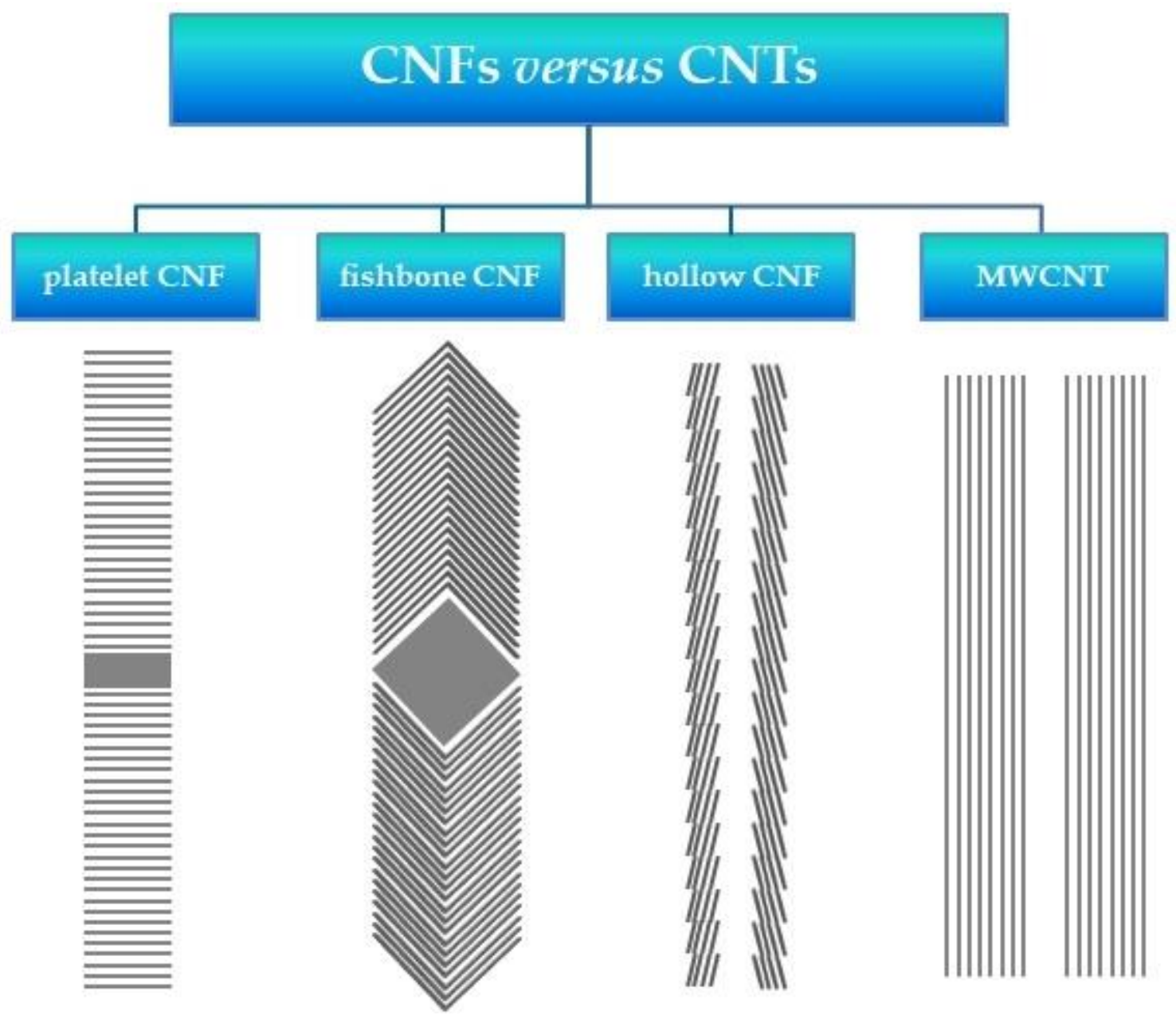


Figure $^{\wedge} 3$ Types of carbon nanotubes. Adapted from ${ }^{[266]}$

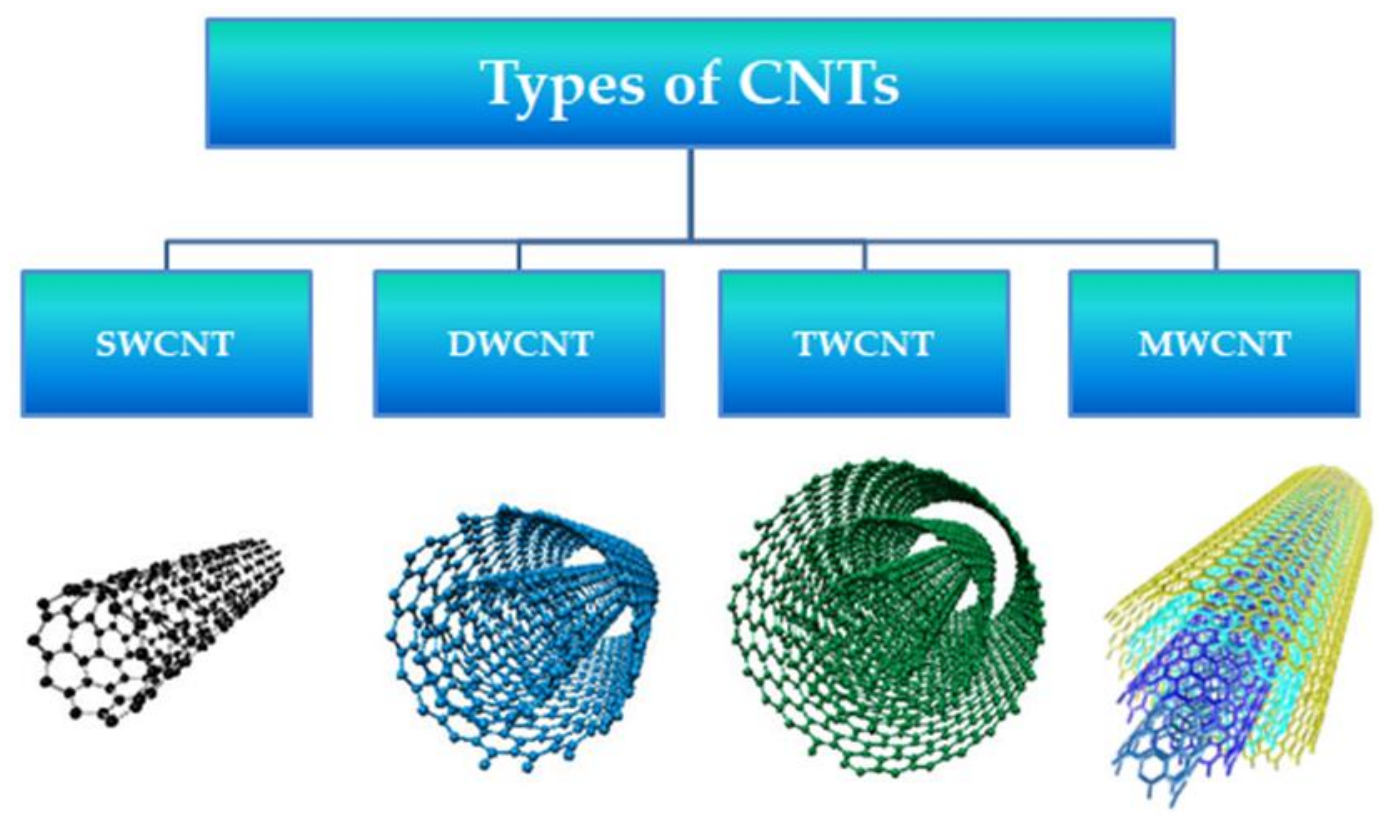

Figure $^{\wedge} 4$ Different chiralities of carbon nanotubes. CNTs structure can possess different chiralities: armchair, zigzag and chiral structures. 


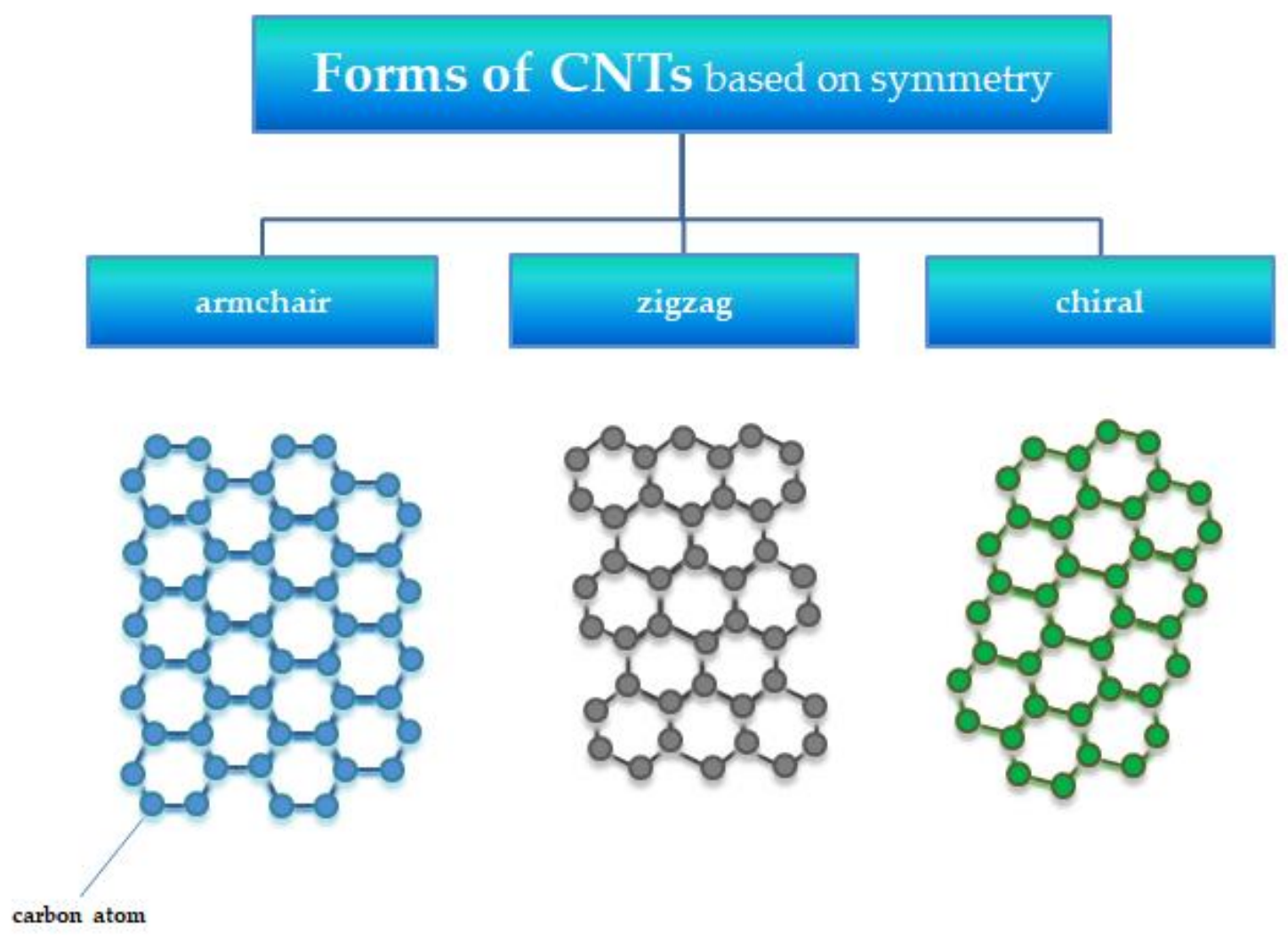

Figure $^{\wedge} 5$ Surface modifications of carbon nanotubes with polymers. To tailor the chemical nature of the nanotube's walls in order to take advantage of their unique properties, two main strategies for the surface modification of CNTs are used, i.^e. covalent and noncovalent, depending on whether or not covalent bonding between the CNTs and the functional groups and/or modifier molecules is involved in the modification surface process. ${ }^{[267]}$ A covalent type of functionalization represents the covalent bond formation, and non-covalent one is due to the van der Waals forces only. ${ }^{[268]}$ Adapted from ${ }^{[267]}$ 


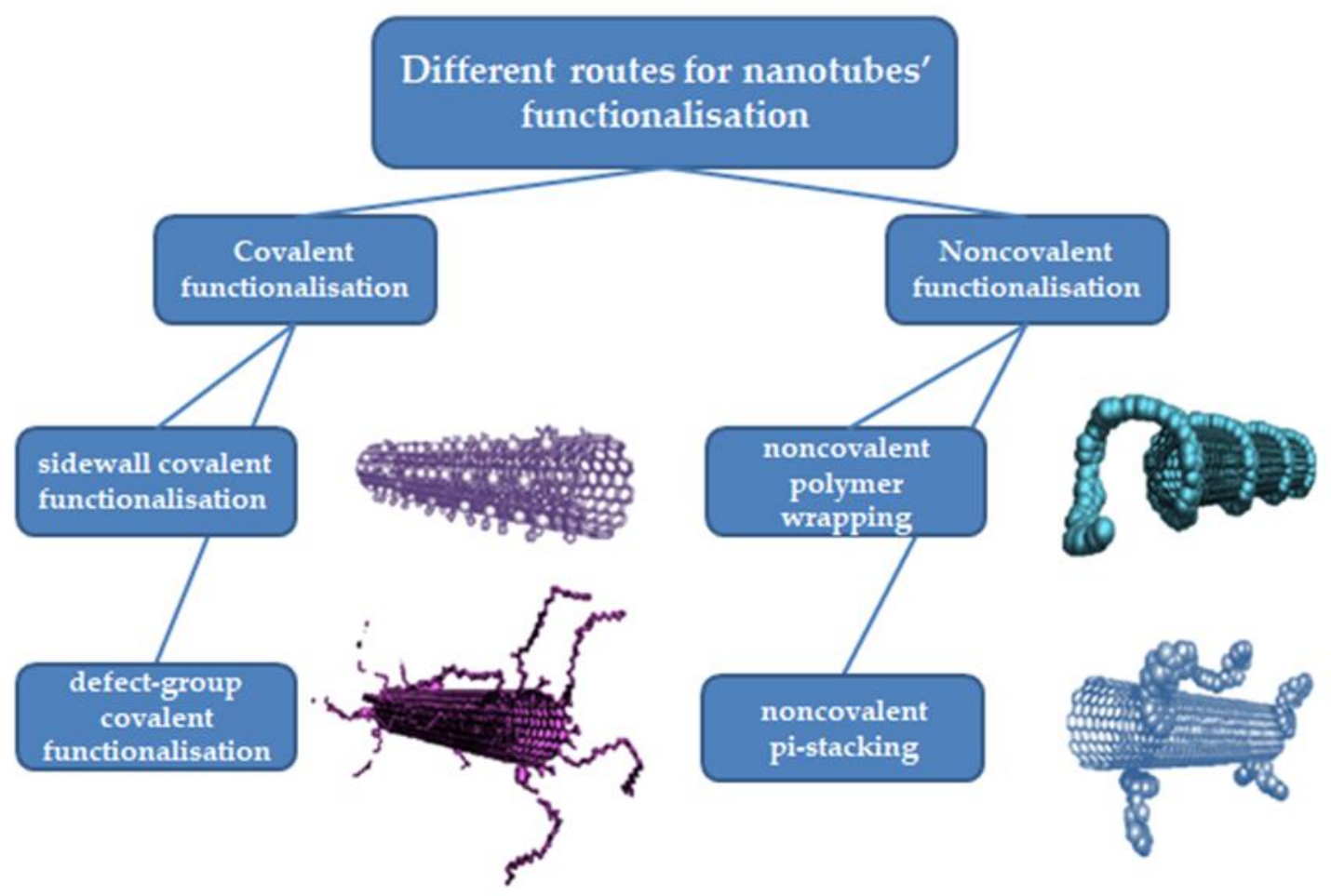

Figure $^{\wedge} 6$ Various approaches for chemical functionalization of CNTs. ${ }^{[190,269-290]}$

Two main types of functionalization, namely, a covalent one, and noncovalent ${ }^{[291]}$ include a variety of different modifications. ${ }^{[285,292--304]}$ 


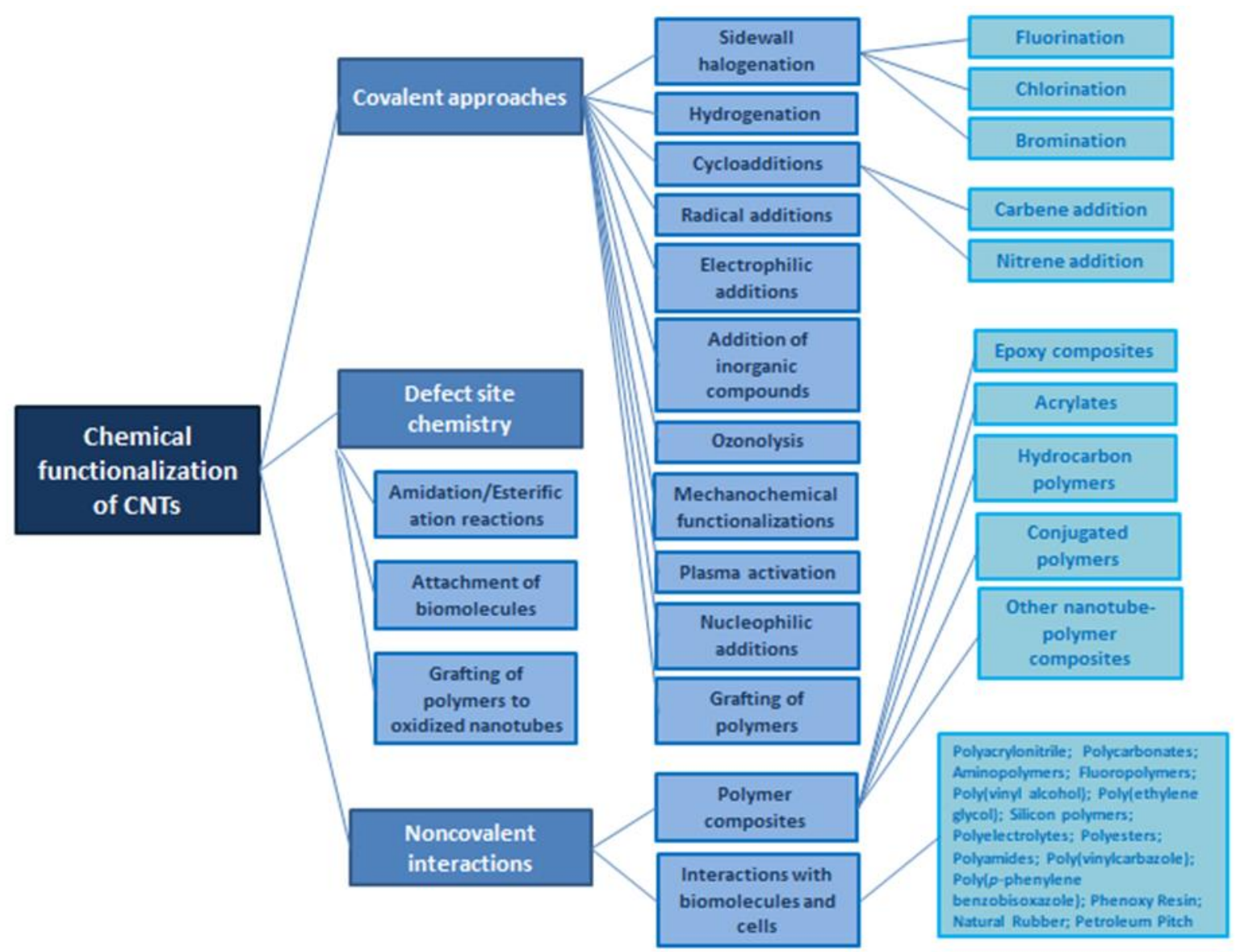


Figure ${ }^{\wedge} 7$ The surface of CNTs. To the surface of the carbon nanotubes, various therapeutic agents, such as an anticancer drug, nucleic acid as well as even antibody can be attached. Nowadays, many types of polymers are used for drug and gene delivery. The most widely used polymers are shown. ${ }^{[218,232,305-310]}$ NHS - N-hydroxysuccinimide; EDC (EDC $\cdot \mathrm{HCl})$ - $N$-(3-dimethylaminopropyl)- $N$ '-ethylcarbodiimide hydrochloride; PVPpolyvinylpyrrolidone; PSS -- polystyrene sulfonate; PmPV -- poly\{(m-phenylenevinylene)$c o-[(2,5-$ dioctyloxy-p-phenylene $)$ vinylene $]\} ;$ PPyPV -- poly $\{(2,6$-pyridinylenevinylene $)-c o-$ $[(2, \wedge 5$-dioctyloxy-p-phenylene $)$ vinylene $]\}$; PAmPV - poly $\{(5$-alkoxy- $m$-phenylenevinylene $)$ co-[(2,5-dioctyloxy-p-phenylene)vinylene $]\}$; PAM -- polyacrylamide; PLGA -- poly(D,Llactide-co-glycolide); PEG -- polyethyleneglycol; PEI - polyethyleneimine 


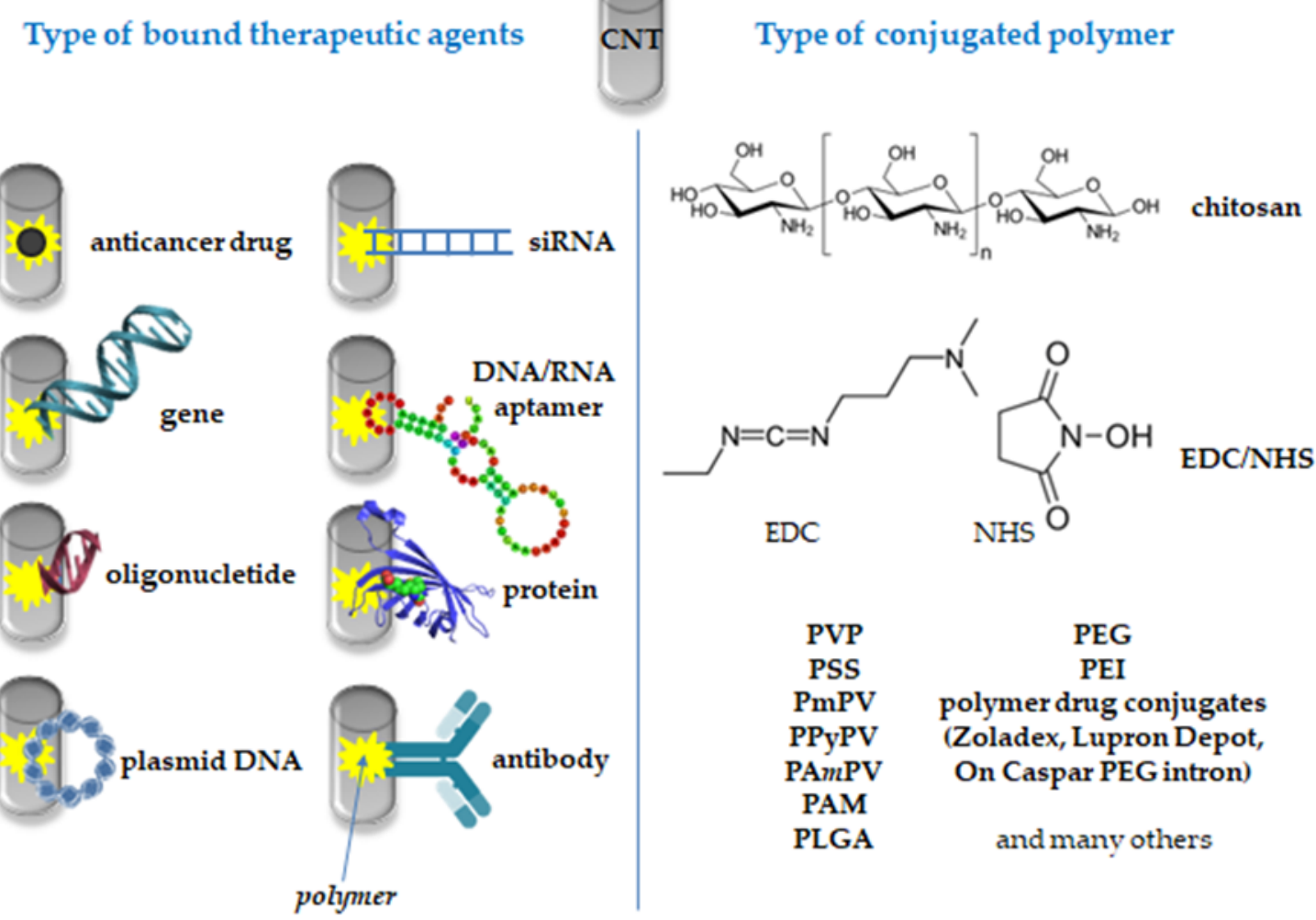

\section{Surface of CNTs}


Figure $^{\wedge \wedge} 8$ Targeted drug delivery and enhanced permeation and retention (EPR) effect in different types of tissues. A -- Targeted drug delivery to hepatocellular carcinoma (HCC) and illustration of EPR effect. For tumor blood vessels, a loss of smooth muscle cells, extracellular matrix degradation, and increased endothelial permeability are typical. ${ }^{[311]}$ The aberrant tumor vasculature together with reduced lymphatic drainage evokes the development of the EPR effect, ${ }^{[255,256,312]}$ leading to the accumulation of nanoparticles at the tumor site. ${ }^{[252]}$ A targeted drug delivery system (here represented by functionalized CNTs loaded with the anticancer drug) uses changes in $\mathrm{pH}$. The drug binds at physiological $\mathrm{pH}\left(\mathrm{pH}^{\wedge \wedge} 7.4\right)$ and is only released at a lower $\mathrm{pH}$ typical for tumor environments. ${ }^{[242]} \mathrm{B}$-- Targeted drug delivery across blood-brain-barrier (BBB) and the assumed EPR effect for CNT-based targeted drug delivery system. The BBB is a highly selective semipermeable membrane barrier that separates the circulating blood from the brain and extracellular fluid in the central nervous system (CNS). Nanoparticles, in contrast to free antitumor drugs, possess the ability to cross the BBB. Therefore they are promising for drug delivery in difficult-to-treat tumors, like brain tumors. The release of anticancer drug from a nanomaterial-based targeted drug delivery system is allowed by similar changes in brain tumor tissue like in other tumors, including a decrease in $\mathrm{pH}$ and hypoxia environment generation. 


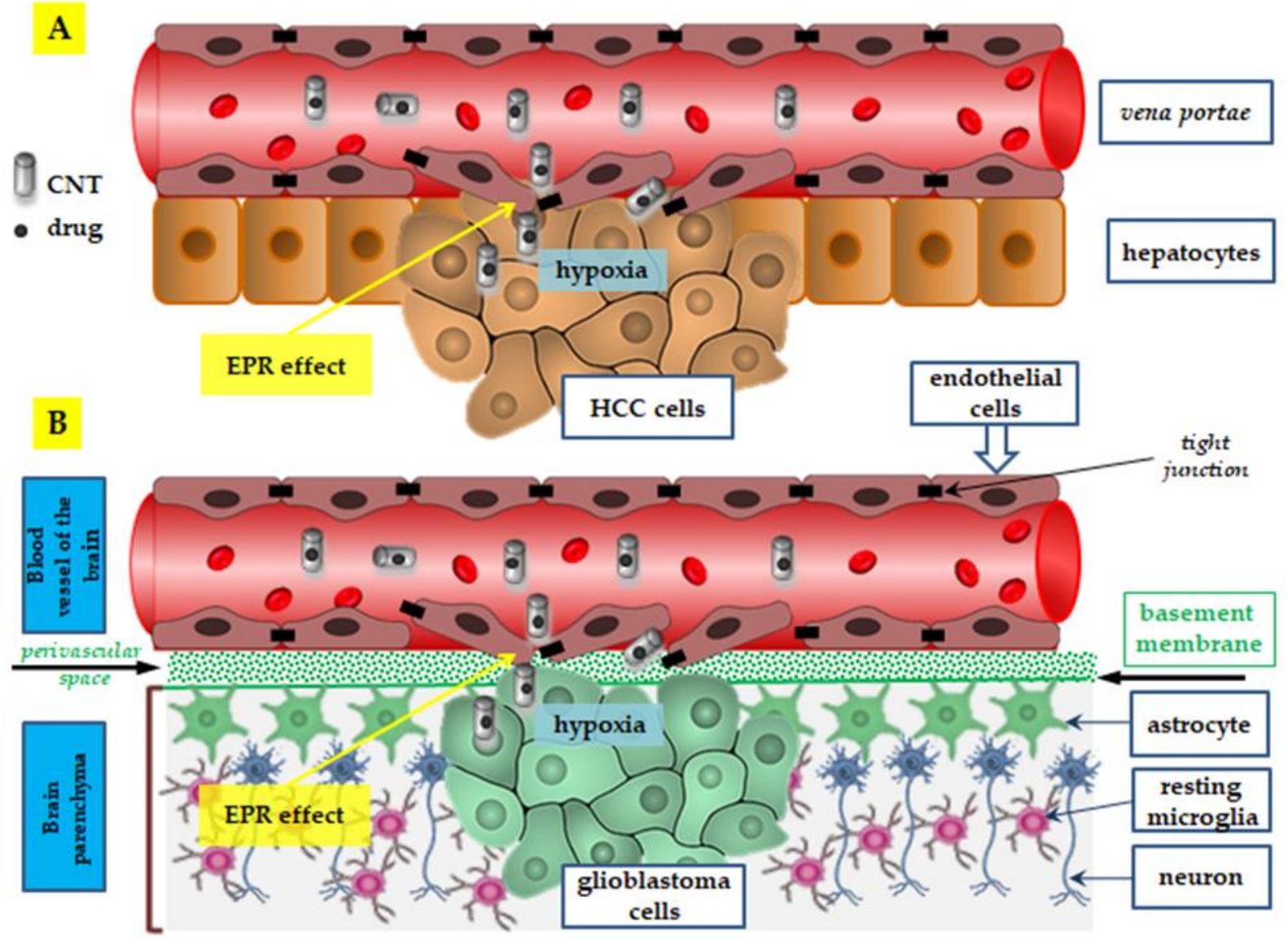

Figure $^{\wedge}$ T 9 The proposed mechanism for the internalization of HSA-CNT-mediated

albumin receptor. Adapted from ${ }^{[313]}$ Gp60 receptor -- albumin receptor; albondin; HSA -human serum albumin; a -- plasma (cell) membrane; b -- cytoplasm; 1 -- caveosome; 2 -early endosome; 3 -- matured (late) endosome. The assumed mechanism for the internalization of HSA-CNT-mediated albumin receptor that is taking place within hepatocellular carcinoma cells (HepG2 cells): CNT internalization involves the selective uptake of HSA-CNT through albumin receptors GP60. The first step is the formation of caveolar invaginations on the surface of the cell membrane, so-called caveosomes. The vesicles are then transformed into early endosomes. Matured (late) endosomes receive the internalized material on the route to lysosomes, usually from the early endosomes in the endocytic pathway, and most of the associated receptors circulate back into the plasma membrane. Late endosomes mediate, and the final set of sorting events before the material is delivered to lysosomes. Lysosomes are the last 
of the endocytic pathway. CNTs are released within the cytoplasm-forming clusters, and HSA is cleaved by lysosomes. ${ }^{[313]}$

$$
\begin{array}{llll}
\hline & \text { drug } & \text { Gp60 } \\
\text { 1) } & \text { CNT } & \bullet & \text { HSA }
\end{array}
$$

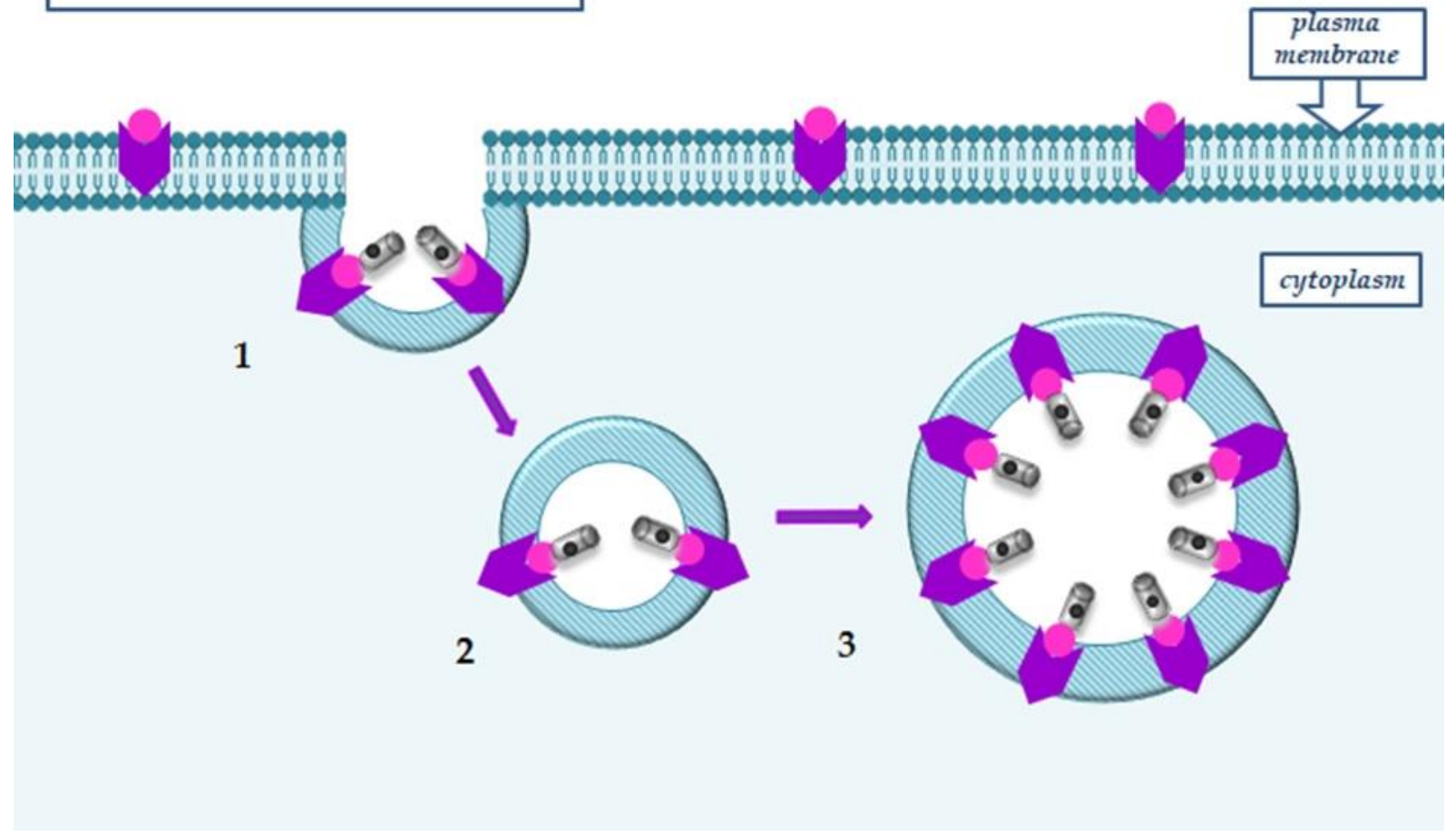

